\title{
O desempenho econômico de Pelotas (1939 - 2009): uma análise comparativa com os principais municípios do interior do RS
}

\author{
César Augusto Oviedo Tejada* \\ Giovani Baggio
}

\section{Resumo}

Este trabalho tem o objetivo de analisar o desempenho econômico do município de Pelotas, entre os anos de 1939 e 2009, uma das principais forças econômicas do Rio Grande do Sul no século XIX e início do século XX. Esta análise é construída comparando as trajetórias percorridas por algumas de suas variáveis econômicas com os principais municípios do interior do estado e com o caminho trilhado pelo próprio Rio Grande do Sul. Os dados revelam que a economia de Pelotas não evoluiu de maneira a acompanhar o crescimento dos principais municípios do interior do estado e do estado. Além disso, Pelotas viu seu vizinho, Rio Grande, manter-se entre as forças econômicas do estado e apresentar tendências de maior avanço econômico, principalmente a partir dos anos 1990. Nesse sentido, foram realizadas algumas projeções com base no recente crescimento da economia pelotense. Mantendo a trajetória atual, o município continuará perdendo espaço na economia gaúcha e tendo baixa evolução em seu PIB per capita.

Palavras-chave: Crescimento econômico. PIB. PIB per capita. Pelotas.

* Professor do Programa de Pós-Graduação em Organizações e Mercados (PPGOM) e do curso de Ciências Econômicas da Universidade Federal de Pelotas (UFPel). E-mail: cesaroviedotejada@ gmail.com.

** Aluno do curso de Ciências Econômicas da Universidade Federal de Pelotas (UFPel) e bolsista PIBIC/CNPq. E-mail: gbaggio.92@gmail.com.

http://dx.doi.org/10.5335/rtee.v0i41.3736

Submissão: 18/01/2013. Aceite: 02/10/2013 


\section{Introdução}

No século XIX, a metade sul estado do Rio Grande do Sul (RS) foi relevante para o desenvolvimento do estado, tanto economicamente como socialmente. Nessa região, encontravam-se dois dos três principais centros urbanos gaúchos, Pelotas e Rio Grande, caracterizando um importante polo comercial e produtivo. Segundo Alonso (1986, p. 86), "[...] o binômio Pelotas/Rio Grande comandava a economia gaúcha até 1860, aproximadamente [...]”. Monasterio e Zell (2004) realizaram uma estimativa da renda per capita dos municípios gaúchos em 1872, mostrando que Pelotas, Porto Alegre e Rio Grande, respectivamente, eram as três cidades mais ricas da Província de São Pedro do Rio Grande do Sul (antigo nome do estado do Rio Grande do Sul).

Na primeira metade do século XX, os dois municípios da metade sul ainda se destacavam pelas altas participações relativas no Produto Interno Bruto (PIB) gaúcho e pelos altos valores de PIB per capita apresentados. Sendo um dos mais populosos e contando com uma economia forte, o município de Pelotas contribuía com grande parcela da produção gaúcha. Em 1939, obteve o segundo maior PIB do estado (ficando apenas atrás da capital, Porto Alegre), e sua participação relativa foi de 5,66\% no PIB total do Rio Grande do Sul. Porém, ao longo do período de 1939 a 2009, viu sua importância econômica decrescer gradativamente. No ano de 2009, seu PIB foi apenas o nono maior do estado e sua participação relativa de apenas $1,78 \%$.

Em termos de PIB per capita, um indicador de desenvolvimento de uma economia, Pelotas também possuía valores expressivos na primeira metade do século XX. No ano de 1939, ocupava a segunda colocação no ranking entre os municípios estudados, com um PIB per capita 1,80 vezes maior que o evidenciado no estado. Entretanto, a partir dos anos 1970, não apresentou um bom desempenho, mais precisamente a partir de 2000, quando esse indicador o consolidou na última colocação entre os principais municípios do interior. Em 2009, o PIB per capita estadual foi 1,72 vezes maior que o de Pelotas.

Essa situação de declínio não ocorreu apenas com Pelotas, mas com a metade sul do estado, conforme apontam Coronel, Alves e Silva:

[...] a partir da crise do ciclo do charque, a região metade sul do Rio Grande do Sul entra em um processo de degeneração econômica que toma proporções cada vez maiores, diminuindo respectivamente sua população e sua renda. Verificou-se que, após o ciclo do charque, a metade sul não teve capacidade para lançar-se em outro ciclo, nem mesmo efetivar-se no processo de industrialização. (2007, p. 40-41). 
De acordo com Friedrich (2002), o Rio Grande do Sul apresenta uma nítida desigualdade entre as regiões Norte e Sul do estado. A metade norte é bem desenvolvida e diversificada tanto na indústria quanto na agropecuária. Já a metade sul, que está baseada no setor de serviços, agricultura, pecuária bovina e indústria (principalmente localizada na mesorregião Sudeste), é bem menos desenvolvida.

Porém, essa decadência da metade sul não ocorreu de forma uniforme em todos os municípios. Rio Grande, que faz divisa territorial com Pelotas, não apresentou a mesma trajetória. Assim como Pelotas, a cidade vizinha teve queda em sua participação no PIB gaúcho, mas demonstrou grande tendência de crescimento nos anos finais do período estudado, atingindo elevados níveis de PIB per capita. Segundo Moraes (2006), o município de Rio Grande desempenha um importante papel como amortecedor do declínio da região, diminuindo os efeitos regionais da decadência econômica de Pelotas, antigo centro dinâmico da economia gaúcha.

Já outros municípios da metade norte do Rio Grande do Sul que eram de importância econômica extremamente baixa em 1939, como Caxias do Sul e Bento Gonçalves (ambos da Serra Gaúcha), surpreenderam com trajetórias de crescimento expressivas, melhorando seus indicadores econômicos.

Diversas pesquisas dedicam-se a explicar os determinantes da diferença regional entre a metade sul e a metade norte do estado, dentre as quais se destacam as de Coronel, Alves e Silva (2007), Moraes (2006), Menezes e Feijó (2008) e Ilha, Alves e Saravia (2002). Dentre os diversos fatores apresentados como determinantes do baixo desenvolvimento da metade sul destacam-se: baixo empreendedorismo e grande conservadorismo dos proprietários de terra da região, baixa densidade demográfica, estrutura produtiva latifundiária, inexistência de economias de aglomeração, falta de integração entre os setores da região e mercado limitado.

Este trabalho analisará a evolução de alguns indicadores econômicos de Pelotas entre 1939 e 2009, comparando seu desempenho frente aos indicadores estaduais, aos regionais ${ }^{1}$ e aos apresentados pelos principais municípios do interior do estado. Procura-se mostrar, com essas comparações, o menor dinamismo apresentado pela economia de Pelotas. Além disso, na parte final deste texto, são realizadas algumas projeções para o futuro da economia pelotense.

$\mathrm{O}$ artigo é relevante, uma vez que são poucos os trabalhos sobre o desempenho econômico de municípios específicos do interior do Rio Grande do Sul ${ }^{2}$. E que não se encontram trabalhos exclusivamente dedicados a analisar o desempenho econômico e realizar projeções para os indicadores do município de Pelotas numa perspectiva de médio prazo. 
Quanto à estrutura do trabalho, além desta introdução, serão apresentadas mais quatro seções. Como não temos disponíveis dados anuais para o período anterior ao ano de 1999, na seção 2 é feita uma análise sob uma perspectiva de médio prazo, utilizando séries com intervalo de tempo de aproximadamente 10 anos abrangendo todo o período estudado. Na seção 3, o período de 1999 a 2009 é observado minuciosamente, contando com a possibilidade de uma análise anual das variáveis. A seção 4 dedica-se a realizar algumas projeções e montar cenários para o futuro da economia de Pelotas. Por fim, na seção 5, são apresentadas as considerações finais.

\section{Período de 1939 a 2009: Uma perspectiva de médio prazo}

O PIB representa a soma (em valores monetários) de todos os bens e serviços finais produzidos numa determinada região, durante um período de tempo. É um dos indicadores mais utilizados na macroeconomia com o objetivo de mensurar a atividade econômica de uma região.

A avaliação do comportamento do PIB por município enfrenta duas dificuldades principais: escassa disponibilidade de dados e metodologia distinta de mensuração de cada instituto (IBGE e FEE, no caso do Rio Grande do Sul). Para ter a maior consistência possível e um horizonte mais longo, utilizamos como fonte $o$ Banco de Dados do Instituto de Pesquisa Econômica Aplicada (IPEADATA), que reúne dados das principais fontes estatísticas brasileiras e internacionais. ${ }^{3}$

Os conceitos utilizados para o cálculo do PIB diferem ao longo do período. Para os anos anteriores a 1999, o conceito utilizado foi o de PIB a custo de fatores. Porém, a partir de 1999, o conceito utilizado é o de preços de mercado ${ }^{4}$. Para uma análise de desempenho real, e não apenas nominal, da evolução das variáveis, as observações do PIB foram deflacionadas para a unidade de $\mathrm{R} \$$ de 2000 . Com isso, elimina-se o efeito do aumento de preços na medida do PIB, que passa a ser denominado PIB real.

Para propósitos de comparação, foram utilizados na análise os 10 principais municípios do interior do Rio Grande do Sul (Bento Gonçalves, Caxias do Sul, Erechim, Lajeado, Passo Fundo, Pelotas, Rio Grande, Santa Cruz do Sul, Santa Maria e Uruguaiana), escolhidos com base em sua respectiva posição no ranking entre os municípios do interior para o PIB real de 2009. ${ }^{5}$ Porém, foram enfatizados os desempenhos de Pelotas e de Rio Grande. 
A seguir, são apresentados os dados da participação relativa dos municípios selecionados no PIB real do RS. Municípios que crescem mais do que a média do estado veem aumentada sua participação no PIB real e vice-versa. Assim, também são mostrados dados das taxas de crescimentos do PIB real dos municípios selecionados ao longo do período. Sabe-se que o PIB real é apenas um indicador de crescimento econômico, portanto, são apresentados dados do PIB real per capita desses municípios. O caminho percorrido pelo PIB setorial influencia na trajetória de desenvolvimento de cada município ou região. Desse modo, dados da evolução do PIB real setorial como percentual do PIB real também constituem o estudo.

\subsection{Evolução da participação do PIB dos municípios gaúchos selecionados no PIB do RS}

A Tabela A1, no apêndice, apresenta dados do PIB real e da evolução da participação relativa dos municípios selecionados entre o período de 1939 a 2009 no PIB real total do Rio Grande do Sul. ${ }^{6}$ Também mostra a posição de cada um no ranking entre os selecionados e em nível estadual ${ }^{7}$, onde também estão incluídos os municípios da Região Metropolitana de Porto Alegre.

O bom desempenho econômico de Pelotas foi notório entre os municípios do Rio Grande do Sul durante a primeira metade do século XX. No período referido, observa-se que a metade Sul teve elevada importância econômica no Rio Grande do Sul. Destacaram-se os municípios de Pelotas e Rio Grande, que juntos somavam uma parcela de 10,41\% sobre o total do PIB real gaúcho no ano de 1939. Nesse ano, Pelotas contribuía com $5,66 \%$, sua maior participação relativa considerando todo o período estudado, sendo que Rio Grande, o segundo colocado no ranking entre os municípios do interior, tinha uma participação também expressiva de $4,75 \%$. Santa Maria, que foi o terceiro, somava uma parcela de apenas 2,27\%, e Erechim, que foi o quarto $1,81 \%$.

Essa expressiva participação relativa conjunta de Pelotas e Rio Grande, no ano de 1939 (10,41\%), não se manteve ao passar dos anos, chegando ao final do período estudado, em 2009, a somar apenas 4,69\%. Para efeito de comparação, as participações relativas de Caxias do Sul, em 1939 e 2009 foram, respectivamente, $1,55 \%$ e $5,80 \%$, ou seja, Caxias do Sul apresentou uma participação relativa maior que os dois municípios juntos em 2009.

O forte e destacado desempenho de Pelotas em 1939 foi mantido até o final da década de 1950. Em 1959, o PIB real de Pelotas representava 5,14\% da produção estadual. Porém, entre os anos de 1959 e 1970 sua participação relativa teve um 
declínio significativo, passando de 5,14\%, em 1959, para 3,21\%, em 1970. Com esse decréscimo, Pelotas perdeu o posto de maior economia do interior para Caxias do Sul (que possuía uma participação relativa de $3,41 \%$ em 1970), e caiu para a quarta colocação no ranking em nível estadual.

Observa-se claramente na Figura 1 que a participação percentual do PIB real de Pelotas no PIB real do Rio Grande do Sul decresceu de forma acentuada a partir de 1959. Seguindo a mesma trajetória declinante, porém mostrando uma consistente recuperação nos últimos anos, Rio Grande fechou o período com uma participação superior à apresentada por Pelotas. O município que apresentou a maior trajetória de crescimento em sua participação relativa no estado foi Caxias do Sul.

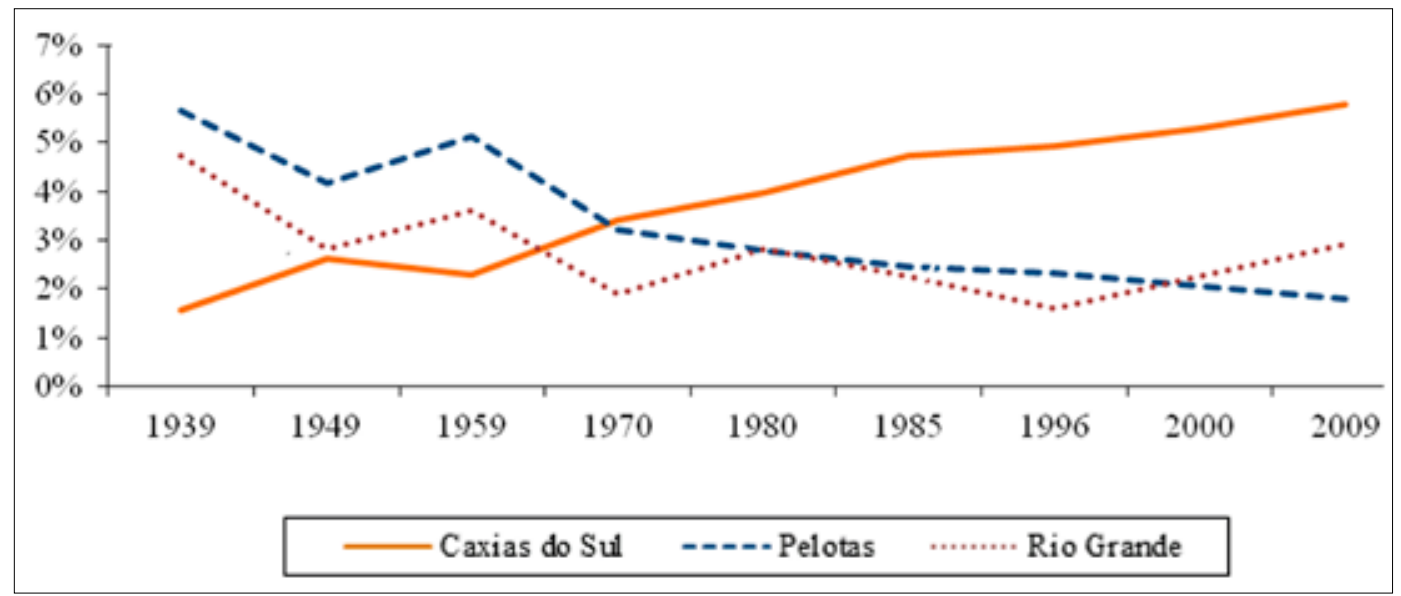

Fonte: Elaborado com base nos dados do IPEADATA.

Figura 1. Participação percentual de Caxias do Sul, Pelotas e Rio Grande no PIB real do RS - 19392009

Dentre todos os municípios estudados, somente Bento Gonçalves, Caxias do Sul, Passo Fundo e Santa Cruz do Sul (todos da metade Norte do estado) conseguiram um aumento em sua participação relativa no PIB real gaúcho comparando o início com o final do período, ou seja, 1939 com 2009. 


\subsection{Evolução das taxas de crescimento do PIB real dos municípios gaúchos selecionados}

No que se refere às taxas de crescimento do PIB real, a Tabela 1 apresenta dados das taxas de crescimento médio anual do PIB real dos municípios selecionados e do Rio Grande do Sul no período de 1939 a $2009 .{ }^{8}$

Tabela 1. Taxas de crescimento médio anual do PIB real (\%) - 1939-2009

\begin{tabular}{l|r|r|r|r|r|r|r|r}
\hline \multirow{2}{*}{ Discriminação } & \multicolumn{7}{|c}{ Taxas de crescimento médio anual (\%) } \\
\cline { 2 - 9 } & \multicolumn{1}{|c|}{$39 / 49$} & \multicolumn{1}{c}{$49 / 59$} & \multicolumn{1}{c}{$59 / 70$} & \multicolumn{1}{c}{$70 / 80$} & $80 / 85$ & $85 / 96$ & \multicolumn{1}{c}{$96 / 00$} & \multicolumn{1}{c}{$00 / 09$} \\
\hline Bento Gonçalves & 10,61 & 4,44 & 8,31 & 12,73 & 1,95 & 0,94 & 4,73 & 1,14 \\
Caxias do Sul & 10,45 & 4,63 & 10,54 & 10,31 & 5,84 & 1,14 & 4,46 & 3,74 \\
Erechim & 9,64 & $-0,28$ & 0,76 & 6,42 & 4,17 & 3,17 & 2,22 & 3,00 \\
Lajeado & 4,91 & 4,04 & 7,36 & 6,45 & $-1,87$ & 3,38 & 2,57 & 3,82 \\
Passo Fundo & 7,22 & 3,71 & 4,67 & 10,43 & $-2,53$ & 2,00 & 8,58 & 2,54 \\
Pelotas & $\mathbf{1 , 5 9}$ & $\mathbf{8 , 3 6}$ & $\mathbf{2 , 1 3}$ & $\mathbf{7 , 0 3}$ & $-\mathbf{0 , 2 7}$ & $\mathbf{0 , 3 4}$ & $\mathbf{- 0 , 7 0}$ & $\mathbf{1 , 1 1}$ \\
Rio Grande & $-0,59$ & 8,76 & 0,46 & 13,16 & $-2,42$ & $-2,22$ & 11,62 & 5,65 \\
Santa Cruz do Sul & 8,99 & 2,47 & 4,12 & 8,56 & 6,48 & $-1,99$ & 10,37 & 4,61 \\
Santa Maria & 3,61 & 4,98 & 6,71 & 6,93 & 2,55 & 2,56 & $-2,29$ & 2,65 \\
Uruguaiana & 3,41 & 4,46 & 6,86 & 8,28 & 3,84 & $-2,14$ & 1,38 & 5,10 \\
Porto Alegre & $\mathbf{4 , 8 7}$ & $\mathbf{6 , 8 2}$ & $\mathbf{7 , 6 5}$ & $\mathbf{7 , 8 7}$ & $-\mathbf{0 , 6 2}$ & $\mathbf{3 , 0 5}$ & $-\mathbf{4 , 9 4}$ & $\mathbf{1 , 1 2}$ \\
Rio Grande do Sul & $\mathbf{4 , 7 5}$ & $\mathbf{6 , 1 1}$ & $\mathbf{6 , 5 9}$ & $\mathbf{8 , 6 2}$ & $\mathbf{2 , 1 8}$ & $\mathbf{0 , 7 9}$ & $\mathbf{2 , 5 3}$ & $\mathbf{2 , 7 3}$ \\
\hline
\end{tabular}

Fonte: Elaborada com base nos dados do IPEADATA.

As taxas de crescimento médio do PIB real de Pelotas mostram um desempenho oscilante no decorrer do período estudado. O município obteve seu maior período de crescimento entre 1949 e 1959, com média de 8,36\%, valor que ficou acima da medida do estado e até mesmo da capital, Porto Alegre, que apresentaram médias de $6,11 \%$ e $6,82 \%$, respectivamente. O desempenho de Pelotas nesse indicador ficou abaixo somente de Rio Grande, que consolidou o maior crescimento médio no período referido, com um valor de $8,76 \%$.

A década de 1970 foi a de melhor desempenho geral entre os municípios estudados, ou seja, praticamente todos tiveram uma média expressiva de crescimento do PIB real. Por consequência disso, o RS obteve sua melhor marca, consolidando um crescimento médio de $8,62 \%$. Pelotas, nesse subperíodo, apresentou uma taxa de 7,03\% - sua segunda melhor marca, e seu município vizinho, Rio Grande, alcançou $13,16 \%$. 
Entre 1996 e 2000, a variação média anual do PIB real de Pelotas ocorreu a taxas negativas de $-0,70 \%$, enquanto Rio Grande obteve sua segunda melhor marca, $11,62 \%$, mostrando o contraste regional entre os dois municípios. O Rio Grande do Sul também não alcançou um valor expressivo (2,53\%) e Porto Alegre obteve uma marca também negativa $(-4,94 \%)$.

A Figura 2 mostra que as taxas de crescimento médio anual de Pelotas sempre ficaram abaixo das apresentadas no estado, com exceção do período entre 1949 e 1959, época em que Pelotas alcançou sua melhor taxa de crescimento médio. O município de Rio Grande apresentou grandes oscilações, mas com valores positivos expressivos a partir dos anos 1990 .

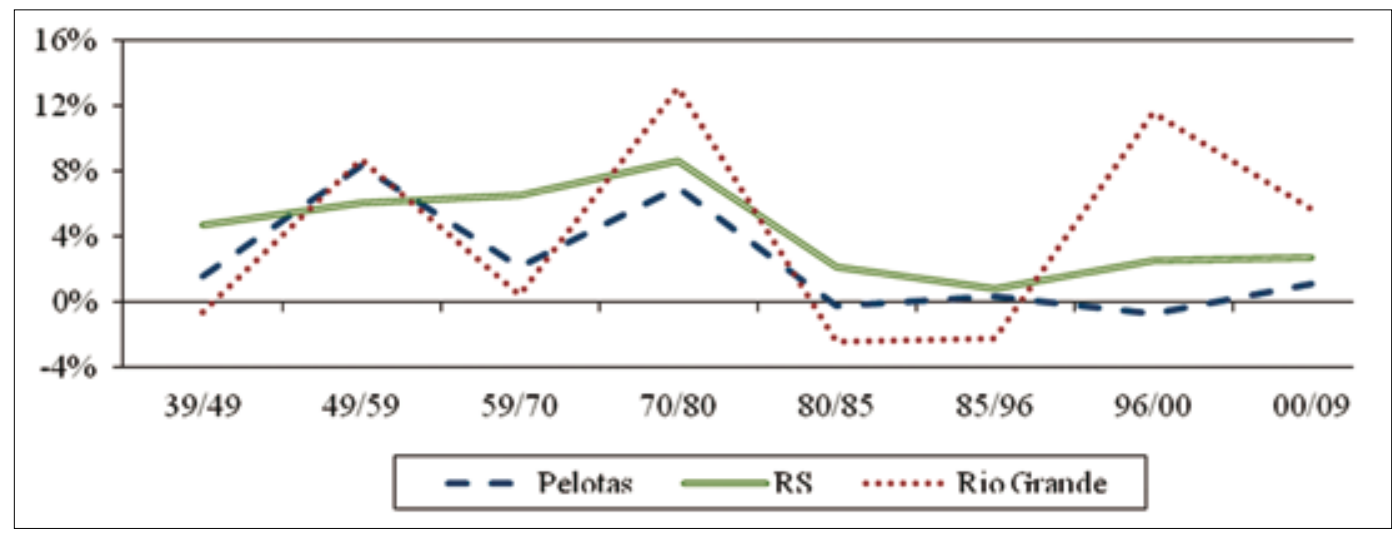

Fonte: Elaborado com base nos dados do IPEADATA.

Figura 2. Taxas de crescimento médio anual de Pelotas, Rio Grande e RS - 1939-2009

\subsection{Evolução do PIB real per capita dos municípios gaúchos selecionados}

O PIB real per capita é comumente considerado a medida do nível médio do desenvolvimento de uma economia ${ }^{9}$. A Tabela 2 apresenta os dados do PIB real per capita dos municípios selecionados e do estado do Rio Grande do Sul. Para cada ano, é apresentado o ranking com a classificação dos 10 municípios.

O PIB real per capita de Pelotas foi expressivo no ano de 1939 ( $\mathrm{R} \$ 2.483,86$ ), o segundo maior entre os municípios selecionados, ficando atrás apenas do município de Rio Grande. Fato que comprova a pujança econômica do Sul do estado no início do século XX. Comparando o PIB per capita de Pelotas com o município que obteve o valor menos expressivo no mesmo ano, Erechim, com $R \$ 778,23$, percebe-se que Pelotas obteve um valor 3,19 vezes maior. 
Tabela 2. PIB real per capita em $\mathrm{R} \$$ de 2000 e ranking - 1939-2009

\begin{tabular}{|c|c|c|c|c|c|c|c|c|}
\hline \multirow{2}{*}{ Discriminação } & \multicolumn{2}{|c|}{1939} & \multicolumn{2}{|c|}{1949} & \multicolumn{2}{|c|}{1959} & \multicolumn{2}{|c|}{1970} \\
\hline & $\mathrm{R} \$$ & Rank. & $\mathrm{R} \$$ & Rank. & $\mathrm{R} \$$ & Rank. & $\mathrm{R} \$$ & Rank. \\
\hline Bento Gonçalves & $1.213,86$ & $7^{\circ}$ & $2.505,07$ & $4^{\circ}$ & $2.839,43$ & $6^{\circ}$ & $5.524,15$ & $2^{\circ}$ \\
\hline Caxias do Sul & $1.791,01$ & $4^{\circ}$ & $3.276,17$ & $1^{\circ}$ & $2.938,65$ & $5^{\circ}$ & $6.271,48$ & $1^{\circ}$ \\
\hline Erechim & 778,23 & $10^{\circ}$ & $1.749,97$ & $8^{\circ}$ & $3.082,46$ & $4^{\circ}$ & $4.539,28$ & $3^{\circ}$ \\
\hline Lajeado & $1.076,45$ & $8^{\circ}$ & $1.484,60$ & $9^{\circ}$ & $1.874,03$ & $10^{\circ}$ & $4.032,95$ & $8^{\circ}$ \\
\hline Passo Fundo & 914,76 & $9^{\circ}$ & $1.445,16$ & $10^{\circ}$ & $2.275,27$ & $8^{\circ}$ & $3.730,99$ & $9^{\circ}$ \\
\hline Pelotas & $2.483,86$ & $2^{\circ}$ & $2.382,99$ & $5^{\circ}$ & $3.809,00$ & $2^{\circ}$ & $4.119,24$ & $7^{\circ}$ \\
\hline Rio Grande & $3.583,91$ & $1^{\circ}$ & $2.637,35$ & $3^{\circ}$ & $4.742,12$ & $1^{\circ}$ & $4.298,67$ & $5^{\circ}$ \\
\hline Santa Cruz do Sul & $1.469,40$ & $5^{\circ}$ & $2.748,38$ & $2^{\circ}$ & $3.176,11$ & $3^{\circ}$ & $4.384,71$ & $4^{\circ}$ \\
\hline Santa Maria & $1.380,60$ & $6^{\circ}$ & $1.792,63$ & $7^{\circ}$ & $2.000,29$ & $9^{\circ}$ & $3.158,04$ & $10^{\circ}$ \\
\hline Uruguaiana & $2.029,15$ & $3^{\circ}$ & $2.025,99$ & $6^{\circ}$ & $2.399,80$ & $7^{\circ}$ & $4.249,91$ & $6^{\circ}$ \\
\hline Porto Alegre & $3.683,97$ & - & $4.094,71$ & - & $4.869,52$ & - & $7.932,61$ & - \\
\hline Rio Grande do Sul & $1.382,31$ & - & $1.752,80$ & - & $2.380,08$ & - & $3.997,79$ & - \\
\hline \multirow{2}{*}{ Discriminação } & \multicolumn{2}{|c|}{1985} & \multicolumn{2}{|c|}{1996} & \multicolumn{2}{|c|}{2000} & \multicolumn{2}{|c|}{2009} \\
\hline & $\mathrm{R} \$$ & Rank. & $\mathrm{R} \$$ & Rank. & $\mathrm{R} \$$ & Rank. & $\mathrm{R} \$$ & Rank. \\
\hline Bento Gonçalves & $12.505,47$ & $2^{\circ}$ & $11.281,62$ & $1^{\circ}$ & $12.345,50$ & $2^{\circ}$ & $11.832,23$ & $5^{\circ}$ \\
\hline Caxias do Sul & $12.784,24$ & $1^{\circ}$ & $11.198,44$ & $2^{\circ}$ & $12.048,48$ & $3^{\circ}$ & $14.110,96$ & $3^{\circ}$ \\
\hline Erechim & $7.426,26$ & $6^{\circ}$ & $8.686,88$ & $5^{\circ}$ & $8.600,70$ & $6^{\circ}$ & $10.653,87$ & $6^{\circ}$ \\
\hline Lajeado & $5.483,03$ & $10^{\circ}$ & $8.967,22$ & $4^{\circ}$ & $9.722,73$ & $5^{\circ}$ & $12.433,24$ & $4^{\circ}$ \\
\hline Passo Fundo & $6.195,68$ & $7^{\circ}$ & $6.609,41$ & $7^{\circ}$ & $8.526,85$ & $7^{\circ}$ & $9.829,19$ & $7^{\circ}$ \\
\hline Pelotas & $6.185,36$ & $8^{\circ}$ & $5.626,07$ & $9^{\circ}$ & $5.207,34$ & $10^{\circ}$ & $5.669,18$ & $10^{\circ}$ \\
\hline Rio Grande & $9.667,33$ & $4^{\circ}$ & $6.687,44$ & $6^{\circ}$ & $9.918,18$ & $4^{\circ}$ & $15.449,07$ & $2^{\circ}$ \\
\hline Santa Cruz do Sul & $11.083,06$ & $3^{\circ}$ & $9.452,85$ & $3^{\circ}$ & $13.090,43$ & $1^{\circ}$ & $18.020,28$ & $1^{\circ}$ \\
\hline Santa Maria & $5.520,26$ & $9^{\circ}$ & $6.203,64$ & $8^{\circ}$ & $5.416,12$ & $9^{\circ}$ & $6.437,59$ & $9^{\circ}$ \\
\hline Uruguaiana & $8.234,33$ & $5^{\circ}$ & $5.356,10$ & $10^{\circ}$ & $5.566,40$ & $8^{\circ}$ & $8.788,59$ & $8^{\circ}$ \\
\hline Porto Alegre & $12.243,27$ & - & $15.686,67$ & - & $12.134,91$ & - & $12.992,37$ & - \\
\hline Rio Grande do Sul & $8.097,99$ & - & $7.683,99$ & - & $8.030,66$ & - & $9.786,01$ & - \\
\hline
\end{tabular}

Fonte: Elaborada com base nos dados do IPEADATA.

Analisando o horizonte de 71 anos que abrange todo o período estudado, percebe-se que a evolução do PIB real per capita do município de Pelotas não acompanhou o crescimento dos demais municípios. Em 1939, o PIB real per capita de Pelotas foi de $\mathrm{R} \$ 2.483,86$. Já em 2009 , fechou o ano com um valor de $\mathrm{R} \$ 5.669,18$, consolidando um crescimento de apenas 2,28 vezes, o mais baixo dentre os municípios selecionados. Os municípios que obtiveram maior crescimento no de PIB real per capita foram: Erechim (13,68 vezes), Santa Cruz do Sul (12,26 vezes) e Lajeado (11,55 vezes).

Fazendo uma comparação em nível regional, possível na Figura 3, percebe-se que o desempenho de Pelotas em termos de PIB real per capita ficou muito abaixo de Rio Grande, e a distância entre os valores desses municípios aumentou ainda mais a partir de 1996. 


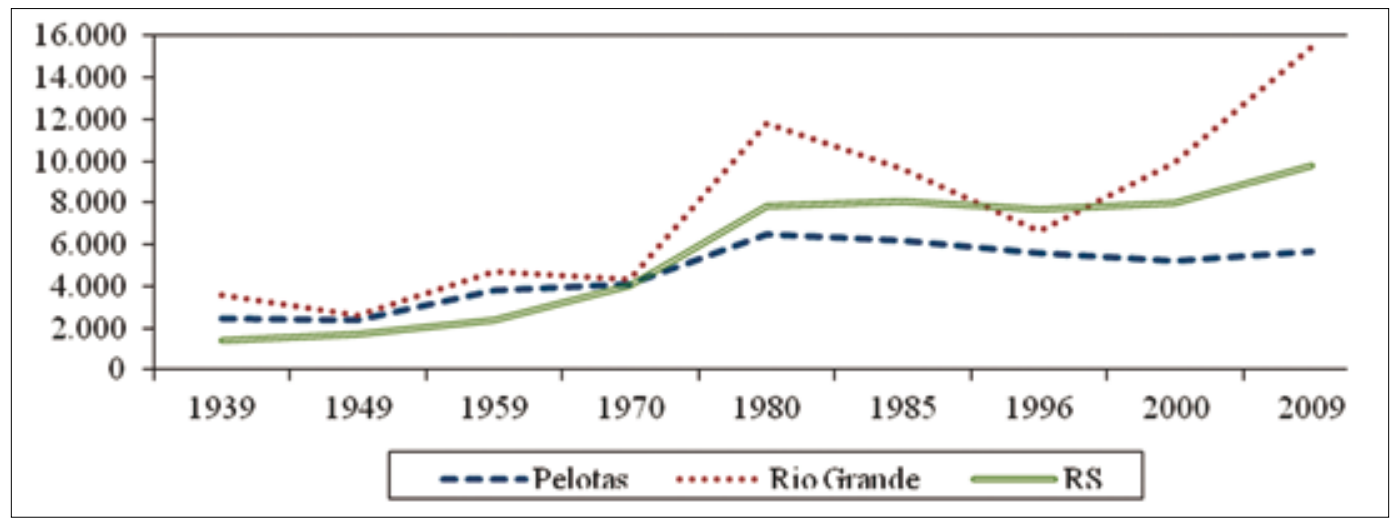

Fonte: Elaborado com base nos dados do IPEADATA.

Figura 3. PIB real per capita de Pelotas, Rio Grande e RS em R\$ de 2000 - 1939-2009

O PIB real per capita de Pelotas ficou acima do nível do Rio Grande do Sul entre 1939 e 1970, sendo que, em 1939, o valor apresentado no estado ( $R \$ 1.382,31)$ atingia apenas $55,65 \%$ do valor apresentado por Pelotas $(\mathrm{R} \$ 2.483,86)$. Porém, no ano de 2009, o PIB real per capita de Pelotas atingia apenas 57,93\% do valor do RS e $36,70 \%$ do valor de Rio Grande.

\subsection{Evolução da participação do PIB real por setores dos municípios gaúchos selecionados}

A Tabela A2, no apêndice, apresenta a evolução da participação do PIB real setorial de cada município e do Rio Grande do Sul em seu respectivo PIB real, entre os anos de 1939 e $2009 .{ }^{10}$

O setor de serviços sempre formou a maior parcela do PIB real de Pelotas no decorrer desses 71 anos estudados, seguido pelo setor industrial e depois pelo setor agropecuário. Essa ordem manteve-se ao longo do período, com apenas uma única exceção ocorrendo no ano de 1939, na qual a parcela da agropecuária foi maior que a da indústria. $\mathrm{O}$ setor de serviços de Pelotas também foi forte antes do período estudado. Para o ano de 1872, Monasterio e Zell destacam que:

Apesar de Porto Alegre ser o maior núcleo urbano gaúcho, o eixo Pelotas-Rio Grande (cidades distantes cerca de $60 \mathrm{~km}$ ) a superava em muitos setores. Na atividade comercial, ambas somam mais que o dobro do que a capital da Província. A mesma superioridade surge no Artesanato: Pelotas e Rio Grande têm mais trabalhadores do tal setor do que Porto Alegre. Isto mostra que são infundadas as visões de que, no sul da Província, a única atividade não agrícola ou pastoril era a charqueada. (2004, p. 6). 
Como mostra a Figura 4, comparando as participações setoriais de 1939 com 2009, percebe-se que o setor agropecuário apresentou um enorme decréscimo em sua participação, passando de $21,59 \%$ para $3,62 \%$. Já o setor da indústria iniciou com uma parcela de 17,52\% em 1939, tendo seu pico nos anos 1980 e fechando 2009 com 18,00\%, praticamente o mesmo valor de 1939.

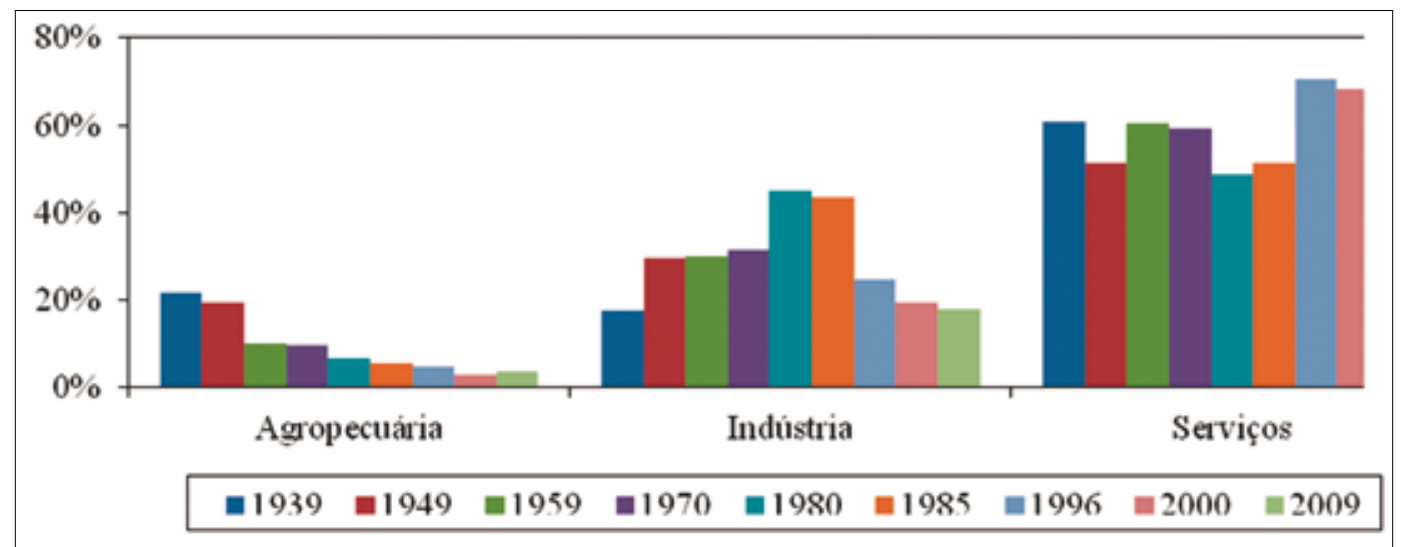

Fonte: Elaborado com base nos dados do IPEADATA.

Figura 4. Evolução da participação relativa do PIB real setorial no PIB real total de Pelotas - 1939-2009

Somente o setor de serviços obteve um crescimento mais expressivo em sua parcela de participação, passando de 60,89\%, em 1939, para 69,97\%, em 2009. Com exceção do ano de 1980 (quando o setor industrial de Pelotas alcançou sua melhor marca), o setor de serviços sempre representou mais de 50\% do PIB real do município.

\section{Olhando mais de perto o período de 1999 a 2009}

A seguir, o período de 1999 a 2009 é analisado minuciosamente, o que é possível por possuir uma série contínua de dados anuais, tornando mais preciso o acompanhamento da evolução das variáveis econômicas estudadas. Para efeito de análise da importância de Pelotas em nível regional, são apresentados os dados sobre o PIB do Conselho Regional de Desenvolvimento da Região Sul (Corede Sul), que é composto por 22 municípios da região Sul do estado, sendo que Pelotas e Rio Grande são os maiores e mais importantes economicamente. ${ }^{11}$ 


\subsection{Trajetória temporal da participação do PIB dos municípios gaúchos selecionados no PIB do RS}

A Tabela A3, no apêndice, mostra a trajetória temporal dos municípios entre 1999 e 2009 no que concerne ao PIB real, tornando possível o acompanhamento contínuo da evoluçãodo PIB dos municípios em face da participação relativa e suas respectivas colocações nos rankings, tanto em nível de interior como em nível estadual.

A participação relativa de Pelotas no PIB do Rio Grande do Sul foi decrescendo ao passar dos anos, mas com algumas pequenas ressalvas de leves altas. Analisando o horizonte de 11 anos, ou seja, comparando sua participação de 1999 (2,28\%) com a de 2009 (1,78\%), percebe-se que houve uma queda de $21,93 \%$.

De 1999 para o ano de 2000, a participação relativa de Pelotas no PIB do estado caiu de 2,28\% para 2,06\%. Esse fato fez Pelotas ser ultrapassado por Rio Grande, que apresentou um crescimento de $5,12 \%$ (passando de $2,15 \%$ para $2,26 \%$ ) no ranking entre os municípios selecionados. A única vez em que o PIB real de Pelotas havia ficado abaixo de seu município vizinho foi em 1980. Porém, a partir de 2001 o PIB real de Rio Grande ficou sempre acima do apresentado em Pelotas. No ano de 2001, ocorreu mais um decréscimo, e a participação de Pelotas no PIB do estado ficou abaixo dos $2 \%$ (mais precisamente 1,98\%), algo que não havia acontecido até o momento, e esse nível não foi mais alcançado até o final do período estudado.

Sob a perspectiva de uma análise regional, a participação relativa de Pelotas sobre o total do PIB real do Corede Sul, seguiu a mesma trajetória decrescente de sua participação no Rio Grande do Sul, resultando num decréscimo de 25,56\% comparando 1999 com 2009. Em termos médios, a participação relativa do município de Rio Grande foi altamente superior se comparada à Pelotas. No período referido, o PIB de Rio Grande teve uma participação média de 40,33\%, enquanto o mesmo indicador de Pelotas constituía, em média, uma parcela de $31,47 \%$.

A Figura 5 mostra o crescimento da participação relativa dos municípios no PIB real estadual de 1999 para 2009. Valores menores que 1 indicam decréscimo, e valores maiores que 1 indicam crescimento na participação. Enquanto a maioria dos municípios apresentou crescimento, sendo constatado o melhor resultado em Rio Grande, Pelotas foi o de menor desempenho. A participação do município em 2009 atingia apenas 78\% de sua participação em 1999. 


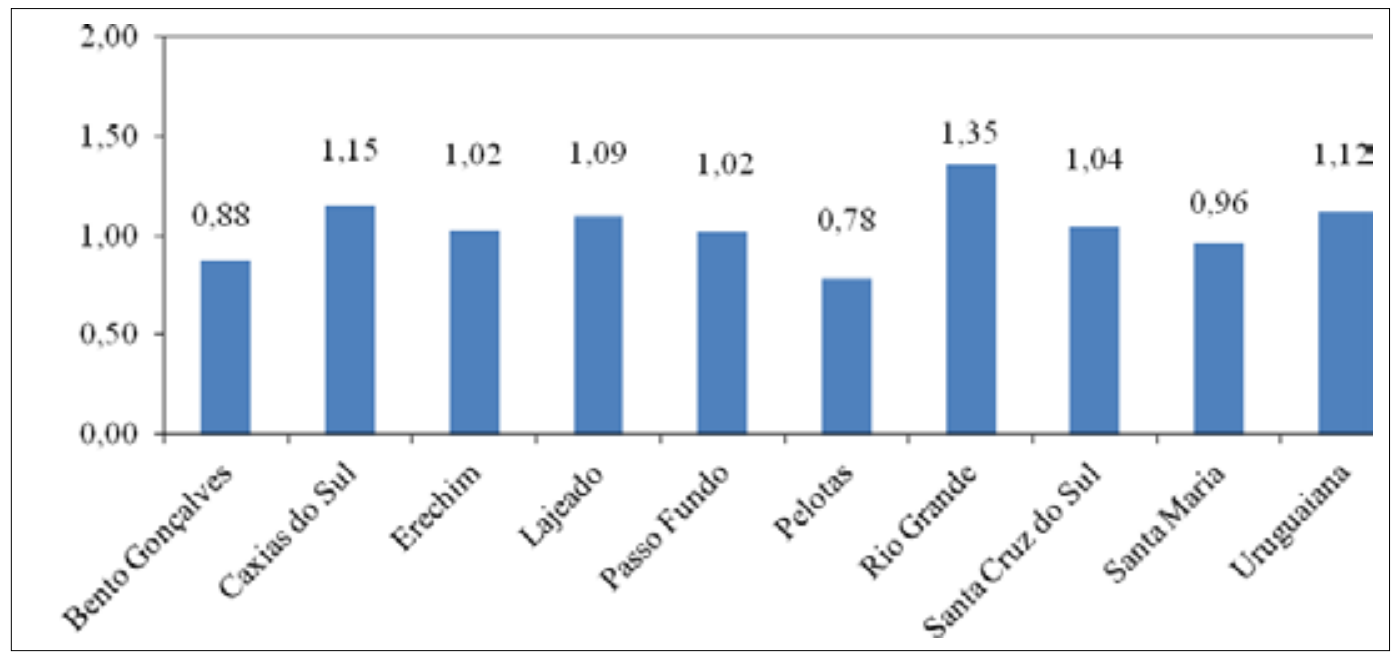

Fonte: Elaborado com base nos dados do IPEADATA.

Figura 5. Crescimento da participação relativa no PIB real do RS de 1999 para 2009

\subsection{Trajetória temporal das taxas de crescimento do PIB real dos municípios gaúchos selecionados}

A Tabela 3 apresenta as taxas de variação anual do PIB real para os municípios selecionados, o Corede Sul e o Rio Grande do Sul entre os anos de 1999 e 2009.

O período que Pelotas alcançou sua maior taxa de crescimento nesses 11 anos foi em 2006, com uma taxa de 4,68\%. O Rio Grande do Sul também obteve sua maior taxa no mesmo ano $(6,38 \%)$, mas com uma taxa superior à apresentada por Pelotas. Rio Grande, que obteve o maior crescimento nesse ano, alcançou uma taxa de $20,65 \%$, e Santa Cruz do Sul, que obteve o pior desempenho, apresentou um decréscimo de $0,25 \%$ em seu PIB real.

No geral, para as unidades estudadas (municípios, Corede Sul e Rio Grande do Sul), o ano de 2004 foi o que demonstrou o desempenho menos expressivo. Rio Grande, que, em 2007, apresentou a maior taxa de crescimento da série (30,97\%), em 2004, apresentou também a maior taxa de decréscimo, que foi de $-14,48 \%$. O Rio Grande do Sul e o Corede Sul também apresentaram suas maiores taxas de decréscimo nesse ano, $-2,40 \%$ e $-8,30 \%$, respectivamente. Seguindo a mesma trajetória, Pelotas obteve sua segunda maior taxa dos 11 anos analisados, com um valor de $-2,21 \%$, ainda assim, ficando acima do apresentado no estado e no Corede Sul. 
Tabela 3. Taxas de variação anual do PIB real (\%) - 1999-2009

\begin{tabular}{l|r|r|r|r|r|r|r|r|r|r|r}
\hline \multicolumn{1}{|c|}{ Discriminação } & $99 / 00$ & $00 / 01$ & $01 / 02$ & $02 / 03$ & $03 / 04$ & $04 / 05$ & $05 / 06$ & $06 / 07$ & $07 / 08$ & $08 / 09$ & Média \\
\hline Bento Gonçalves & 4,81 & $-3,18$ & 2,98 & $-5,80$ & 8,06 & 5,25 & $-2,09$ & 4,64 & $-7,07$ & 8,92 & 1,65 \\
Caxias do Sul & 9,65 & 1,47 & 2,98 & 1,80 & 9,43 & 3,40 & $-2,23$ & 7,42 & 11,31 & $-1,13$ & 4,41 \\
Erechim & 4,07 & 4,47 & $-7,43$ & 14,29 & $-3,53$ & $-0,86$ & 1,77 & 13,55 & 3,09 & 3,63 & 3,30 \\
Lajeado & 3,28 & $-4,19$ & 7,51 & 6,16 & 9,90 & $-0,46$ & 3,40 & 3,27 & 3,48 & 6,06 & 3,84 \\
Passo Fundo & 7,62 & $-4,38$ & 11,25 & 6,25 & $-1,64$ & $-5,34$ & 2,62 & 10,73 & 2,98 & 1,80 & 3,19 \\
Pelotas & $-\mathbf{6 , 2 1}$ & $-\mathbf{0 , 3 2}$ & $\mathbf{1 , 4 2}$ & $-\mathbf{4 , 0 1}$ & $\mathbf{3 , 7 4}$ & $\mathbf{- 2 , 2 1}$ & $\mathbf{2 , 4 8}$ & $\mathbf{4 , 6 8}$ & $\mathbf{1 , 9 4}$ & $\mathbf{2 , 5 7}$ & $\mathbf{0 , 4 1}$ \\
Rio Grande & 9,47 & 8,32 & 5,70 & 2,39 & 2,42 & $-14,48$ & 8,66 & 20,65 & 30,97 & $-7,03$ & 6,71 \\
Santa Cruz do Sul & $-7,96$ & 8,11 & 7,67 & 2,51 & 12,64 & $-5,17$ & $-7,33$ & $-0,25$ & 4,86 & 21,48 & 3,66 \\
Santa Maria & 0,49 & $-2,41$ & 8,29 & 0,71 & 3,53 & 1,76 & 6,34 & 4,19 & 0,94 & 0,92 & 2,48 \\
Uruguaiana & $-4,89$ & 11,30 & 7,67 & $-9,98$ & 7,67 & 26,74 & 4,01 & 9,13 & 5,27 & $-11,07$ & 4,59 \\
Porto Alegre & $-0,24$ & $-1,36$ & 3,93 & $-5,68$ & 0,64 & 10,35 & 0,90 & 5,30 & $-1,50$ & $-1,65$ & 1,07 \\
Corede Sul & $\mathbf{0 , 7 4}$ & $\mathbf{5 , 3 7}$ & $\mathbf{2 , 7 4}$ & $\mathbf{1 , 3 8}$ & $\mathbf{3 , 4 9}$ & $\mathbf{- 8 , 3 0}$ & $\mathbf{4 , 8 4}$ & $\mathbf{1 1 , 6 8}$ & $\mathbf{1 5 , 4 3}$ & $\mathbf{- 1 , 8 5}$ & $\mathbf{3 , 5 5}$ \\
Rio Grande do Sul & $\mathbf{4 , 1 1}$ & $\mathbf{3 , 5 4}$ & $\mathbf{3 , 3 7}$ & $\mathbf{3 , 8 2}$ & $\mathbf{2 , 4 3}$ & $\mathbf{- 2 , 4 0}$ & $\mathbf{2 , 4 4}$ & $\mathbf{6 , 3 8}$ & $\mathbf{4 , 2 7}$ & $\mathbf{0 , 9 5}$ & $\mathbf{2 , 8 9}$ \\
\hline
\end{tabular}

Fonte: Elaborada com base nos dados do IPEADATA.

As expressivas taxas de crescimento de Rio Grande entre 2006 e 2008 devem-se aos investimentos no Polo Naval da cidade, tendo como grande feito a construção da Plataforma de petróleo P-53 da Petrobras, que foi concluída em 2008.

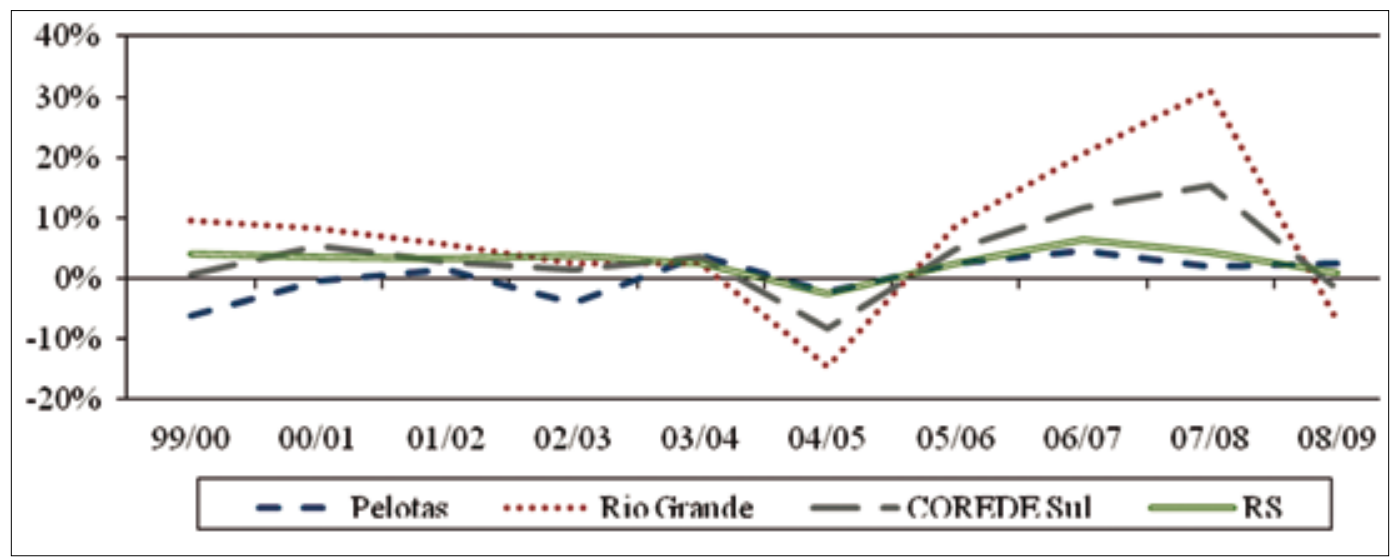

Fonte: Elaborado com base nos dados do IPEADATA.

Figura 6. Trajetória temporal das taxas de variação anual do PIB real de Pelotas, Rio Grande, Corede Sul e RS - 1999-2009 
A Figura 6 evidencia que a taxa de variação média anual do PIB real de Pelotas, praticamente durante todo o período, ficou abaixo de Rio Grande, abaixo do nível regional representado pelo Corede Sul e também do nível estadual. Vale frisar que Rio Grande foi o município que apresentou a maior taxa média de crescimento dentre todas as unidades estudadas, alcançando um valor de 6,71\%. Em contraste a isso, o município de Pelotas apresentou o desempenho mais baixo nesse indicador, com um crescimento médio anual de apenas $0,41 \%$.

\subsection{Trajetória temporal do PIB real per capita dos municípios gaúchos selecionados}

A Tabela A4, no apêndice, apresenta a trajetória temporal do PIB real per capita dos municípios selecionados, do Corede Sul e do estado. Entre 1999 e 2009, percebe-se que esse indicador de Pelotas permaneceu praticamente constante no período referido, tendo seu ápice em 2009 , com $\mathrm{R} \$ 5.669,18$, e seu menor nível em 2003, com R\$5.044,02.

Mesmo Pelotas permanecendo entre as quatro primeiras colocações em termos de PIB real no ranking em nível de interior, em relação ao PIB real per capita a situação foi diferente. Com uma população numerosa de mais de 300 mil habitantes, o município ficou com a nona colocação em 1999 e, a partir do ano de 2000, sustentou a última colocação no ranking. Em valores médios, Pelotas apresentou o menor indicador ( $\mathrm{R} \$ 5.317,80$ ), uma média muito inferior à apresentada em Santa Cruz do Sul ( $R \$ 15.103,94)$, município que apresentou o maior valor.

Comparando a trajetória temporal do PIB real per capita de Pelotas com o do Corede Sul na Figura 7, percebe-se que o valor apresentado no município nunca ficou acima do apresentado por esse último, e a distância entre os valores foi aumentando ao passar dos anos. Em 1999, o PIB real per capita de Pelotas atingia uma parcela de 95,77\% do mesmo indicador do Corede Sul. Porém, em 2009 essa parcela diminuiu para 70,96\%. Os resultados na comparação de Pelotas com o Rio Grande do Sul não diferem muito aos resultados da comparação com o Corede Sul. Sendo assim, a distância entre os valores apresentados no município e no estado também foi aumentando. O PIB real per capita de Pelotas, em 1999 atingia, uma parcela de $72,03 \%$ do PIB real per capita gaúcho. Já em 2009, a fração diminuiu para 57,93\%.

O município de Rio Grande, que também pertence ao Corede Sul, apresentou um desempenho muito diferente ao de Pelotas nesse período. Com uma média anual de $\mathrm{R} \$ 11.763,23$, o município obteve a terceira colocação no ranking dos valores médios. Além disso, a trajetória percorrida pelo PIB real per capita de Rio Grande 
ficou acima da apresentada no Corede Sul e também no Rio Grande do Sul, destacando ainda mais seu expressivo desempenho.

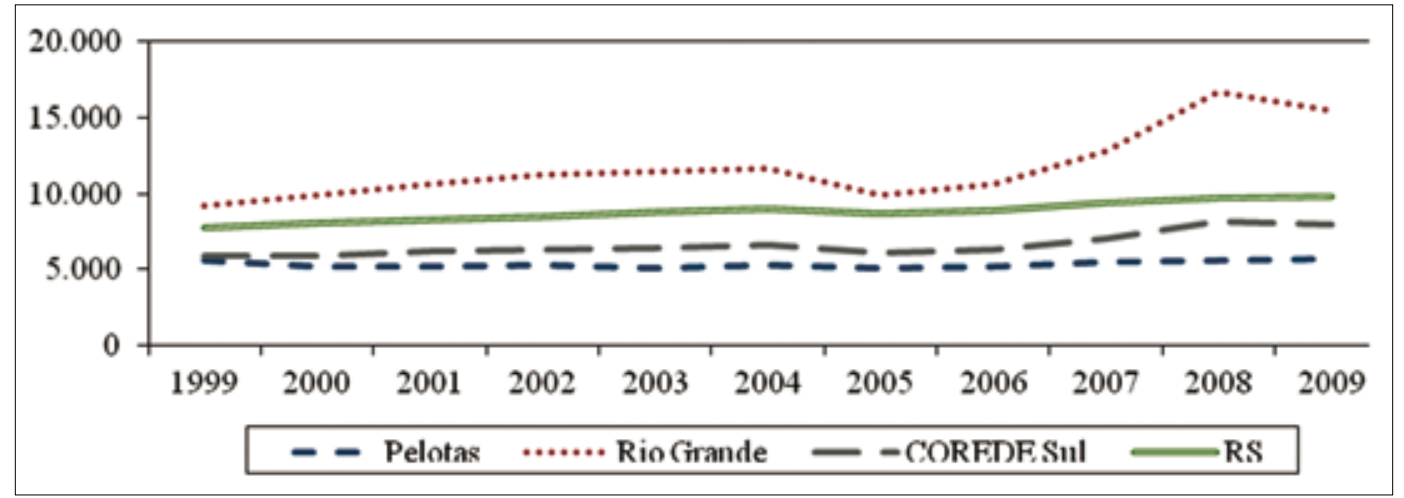

Fonte: Elaborado com base nos dados do IPEADATA.

Figura 7. Trajetória temporal do PIB real per capita de Pelotas, Rio Grande, Corede Sul e RS em R\$ de 2000 - 1999-2009

\subsection{Trajetória temporal do PIB real por setores dos municípios gaúchos selecionados}

A Tabela A5, no apêndice, apresenta dados anuais do PIB real setorial para os municípios em estudo, o Corede Sul e o Rio Grande do Sul, entre 1999 e 2009. Nesse período, podemos observar a trajetória temporal dos três setores principais da economia que compõem o PIB (agropecuária, indústria e serviços), além dos impostos sobre produtos. ${ }^{12}$

Comparando os dados de Pelotas com os dados do Corede Sul e do Rio Grande do Sul, nota-se que a parcela de seu PIB real do setor agropecuário sempre ficou abaixo do nível regional e também do estadual. Em média, esse setor representou $3,21 \%$ do PIB real de Pelotas, enquanto a média do mesmo setor para o Corede Sul e para o estado foi altamente superior, representando uma parcela de 10,48\% para e para o estado $8,51 \%$. Com o setor industrial, essa situação repetiu-se, com a média apresentada em Pelotas ao longo desses 11 anos ficando abaixo da média regional e estadual. O PIB do setor industrial representou, em média, $18,20 \%$ do PIB real de Pelotas, enquanto a média foi de $21,92 \%$ no Corede Sul e de $24,81 \%$ no Rio Grande do Sul. 
No entanto, o setor de serviços de Pelotas sempre apresentou valores altamente expressivos se comparados aos regionais e estaduais. A parcela desse setor, para Pelotas, apresentou uma média de $69,01 \%$, enquanto, no Corede Sul, esse valor foi de 54,31\% e, no Rio Grande do Sul, de 53,73\%.

Analisando a Figura 8, percebe-se que a estrutura setorial de Pelotas não se alterou de maneira expressiva ao longo do período entre 1999 e 2009. O PIB real de Pelotas, em 1999, tinha como composição: 2,52\% agropecuária, 19,91\% indústria, $67,83 \%$ serviços e $9,73 \%$ impostos sobre produtos. Já em 2009, pequenas alterações ocorreram nas proporções em relação a 1999, fechando o ano com: 3,62\% agropecuária, $18,00 \%$ indústria, $69,97 \%$ serviços e $8,42 \%$ impostos sobre produtos. Vale ressaltar que o setor de serviços, que já é responsável por grande parcela do PIB do município, apresenta uma tendência de aumento.

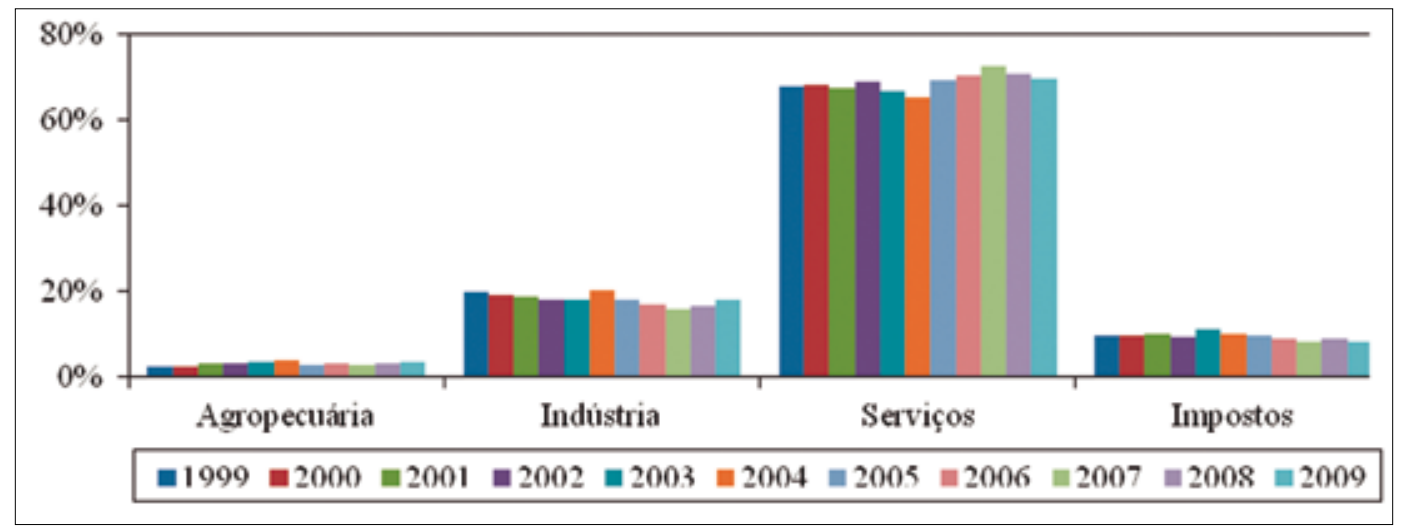

Fonte: Elaborado com base nos dados do IPEADATA.

Figura 8. Evolução da participação relativa do PIB real setorial no PIB real total de Pelotas - 19992009

\section{$4 \mathrm{O}$ futuro: tendências e cenários}

Dado o modesto desempenho da economia de Pelotas no período analisado, buscamos projetar o que acontecerá no futuro com base nas suas trajetórias atuais de crescimento. Investigar o futuro de uma economia não significa prevê-lo, mas sim estudar suas tendências buscando reduzir a incerteza e projetar cenários possíveis que possam servir de referência para a construção de trajetórias de desenvolvimento. 
A partir dos dados entre 1999 e 2009, foram calculadas as taxas de crescimento geométricas do PIB real e do PIB real per capita de Pelotas, Rio Grande e do Rio Grande do Sul. O modelo econométrico utilizado para as estimações foi o seguinte ${ }^{13}$ :

$$
Y_{t}=Y_{0}(1+r)^{t}
$$

onde $Y_{t}$ é o valor observado da variável no período $t$ e $Y_{0}$ seu valor inicial, ou seja, para o ano de 1999. A taxa de crescimento geométrica é representada por $r$. Aplicando o logaritmo natural na equação (1), podemos escrever:

$$
\ln Y_{t}=\beta_{0}+\beta_{1} t
$$

Considerando:

$$
\begin{gathered}
\beta_{0}=\ln Y_{0} \\
\beta_{1}=\ln (1+r)
\end{gathered}
$$

Os coeficientes a serem estimados são $\beta_{0}$ e $\beta_{1}$ e o regressor $t$ assumirá valores discretos que representam os anos, começando com $t=0 \mathrm{em}$ 1999. Incluindo o termo de erro na equação (2), obtemos o modelo a ser estimado por Mínimos Quadrados Ordinários (MQO):

$$
\ln Y_{t}=\beta_{0}+\beta_{1} t+u_{t}
$$

Após as estimações, com o objetivo de encontrar as taxas de crescimento geométricas $(r)$ do período 1999-2009, substituem-se os valores dos coeficientes estimados na equação (4).

As taxas estimadas são utilizadas nas projeções para o período 2010-2030, com a construção de três cenários para o futuro da economia de Pelotas. O primeiro leva em conta a taxa de crescimento calculada com base nas observações do próprio município no período 1999-2009. Para o segundo, supomos que as taxas de crescimento das variáveis econômicas de Pelotas crescem à mesma taxa do estado. E, no terceiro, projetamos os valores supondo que a expressiva taxa de crescimento apresentada por Rio Grande durante 1999-2009 aconteça também na economia pelotense. $\mathrm{O}$ método de estimação descrito é utilizado tanto para projeções do PIB real como para o PIB real per capita. 


\subsection{Tendências e cenários para o PIB real}

A Tabela 4 apresenta as taxas de crescimento do PIB real de Pelotas e Rio Grande, com base nas observações de tal variável entre 1999-2009, além das respectivas participações no PIB estadual. Três cenários também são projetados para o futuro da economia de Pelotas.

Nos últimos anos, a tendência de queda na participação relativa de Pelotas no PIB do Rio Grande do Sul ainda se mostrou presente. Crescendo a uma taxa média de $0,60 \%$, muito abaixo da calculada para o estado $(2,70 \%)$, a tendência é que o PIB do município continue perdendo espaço no PIB gaúcho. Pelos resultados das estimações, em 2020, Pelotas será responsável por 1,42\% da produção gaúcha e, em 2030, esse valor diminuirá para $1,15 \%$.

Seguindo um caminho inverso, Rio Grande demonstra uma tendência de aumento em sua participação relativa no PIB do estado. Com uma taxa de crescimento de $5,28 \%$, sua participação projetada para o ano de 2020 é de $3,82 \%$ e de $4,90 \%$ para 2030.

Tabela 4. Projeções e cenários para a participação relativa do PIB real de Pelotas no PIB real do RS - 2020-2030

\begin{tabular}{l|r|r|r|r|r}
\hline \multirow{2}{*}{ Discriminação } & \multirow{2}{*}{$\begin{array}{c}\text { Taxa de crescimento } \\
\text { geométrica }(r)\end{array}$} & \multicolumn{2}{|c|}{$\begin{array}{c}\text { Último PIB observado } \\
\left(Y_{2009}\right) \text { e \% no PIB do RS }\end{array}$} & \multicolumn{2}{|c}{$\begin{array}{c}\text { (\%) no PIB do RS } \\
\text { Participação } \\
\text { estimada }\end{array}$} \\
\cline { 3 - 6 } & & 2009 & $\%$ & 2020 & 2030 \\
\hline Pelotas atual & $0,60 \%$ & $1.858 .219,72$ & 1,78 & 1,42 & 1,15 \\
Pelotas = Rio Grande do Sul & $2,70 \%$ & $1.858 .219,72$ & 1,78 & 1,78 & 1,78 \\
Pelotas = Rio Grande & $5,28 \%$ & $1.858 .219,72$ & 1,78 & 2,34 & 3,00 \\
Rio Grande & $5,28 \%$ & $3.033 .116,73$ & 2,91 & 3,82 & 4,90 \\
\hline
\end{tabular}

Nota: Último PIB real observado em R \$ de 2000 (mil).

Fonte: Cálculos dos autores.

Analisando a Figura 9, fica clara a divergência de trajetórias entre os dois municípios do Sul do estado, com Pelotas perdendo espaço na economia gaúcha enquanto Rio Grande segue um caminho de rápida ascendência. Obviamente, esse cenário pessimista para a economia de Pelotas assume que não aconteçam mudanças significativas nas economias do RS, de Rio Grande e de Pelotas. 


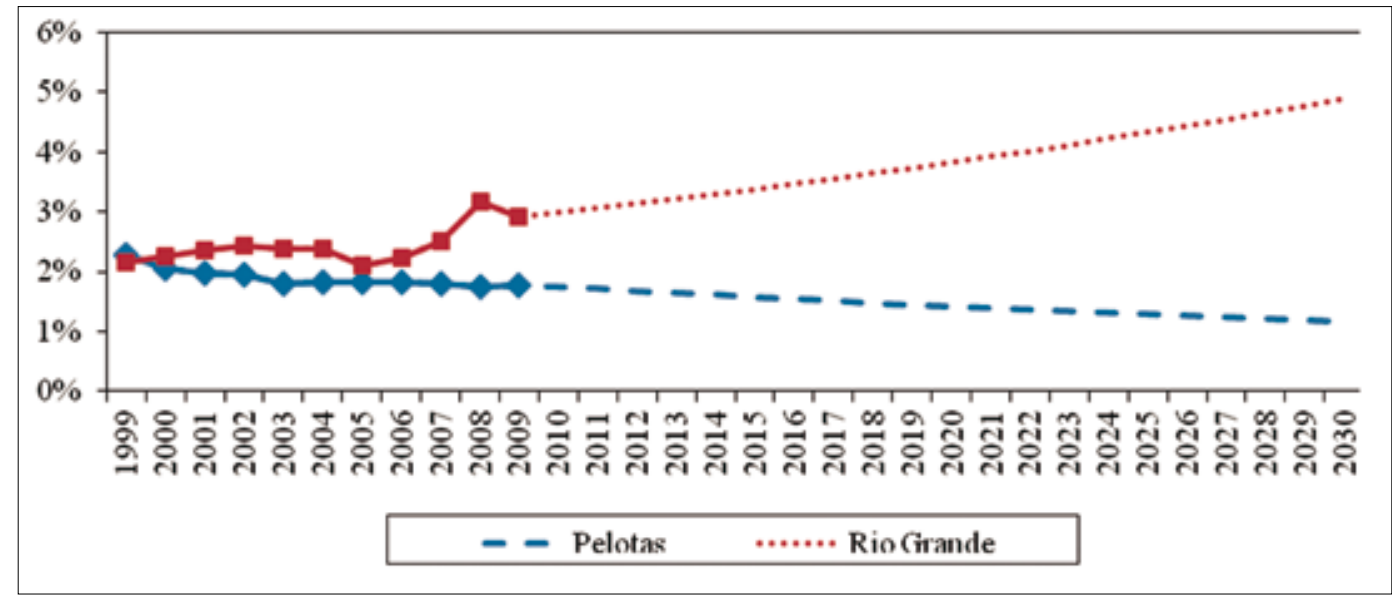

Fonte: cálculos dos autores.

Figura 9. Trajetória das projeções para a participação relativa do PIB real de Pelotas e Rio Grande no PIB real do RS - 1999-1930

O último PIB real de Pelotas observado foi em 2009 e representava 1,78\% do PIB estadual. Levando em conta que seu crescimento seja igual ao apresentado pelo Rio Grande do Sul, sua participação será constante ao longo do tempo, mantendo-se no nível de $1,78 \%$. Por outro lado, confirmando-se o transbordamento da pujante economia de Rio Grande para a de Pelotas, com suas taxas de crescimento igualando-se em 5,28\%, a participação do município no PIB estadual aumentará consideravelmente, chegando ao ano de 2030 com um valor de 3,00\%, algo que não acontecia desde 1970.

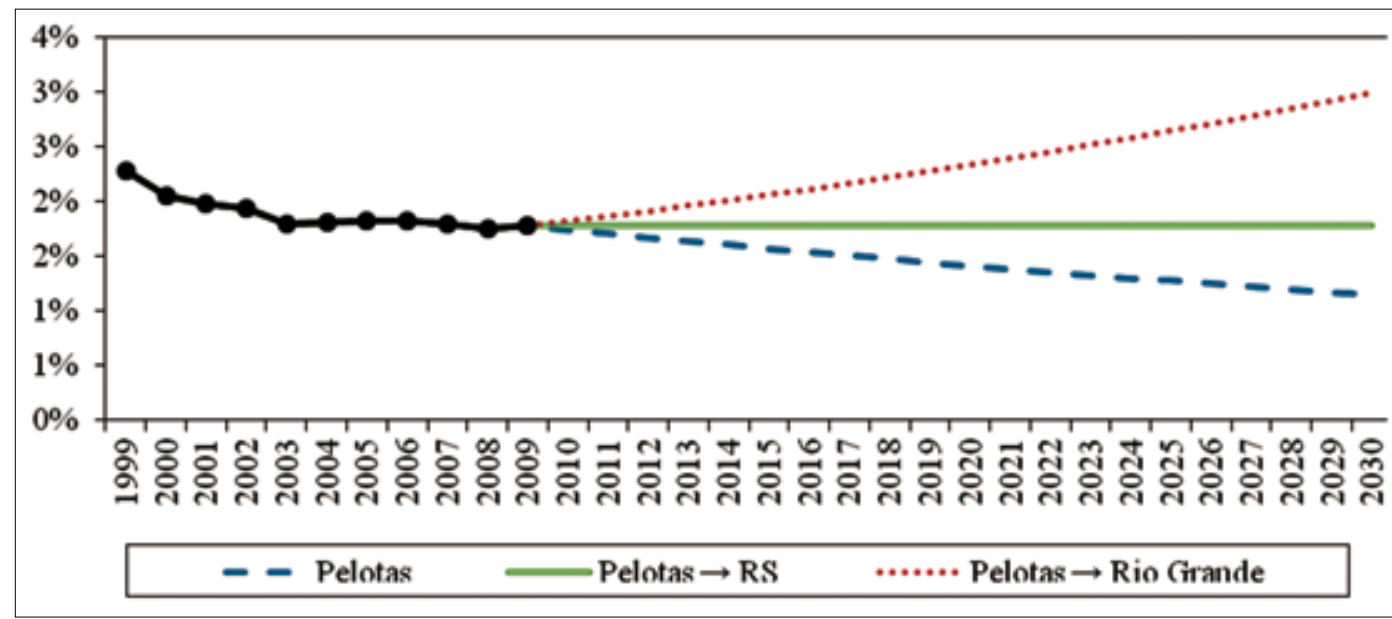

Fonte: cálculos dos autores.

Figura 10. Trajetória da participação relativa do PIB real de Pelotas no PIB real do RS para os cenários projetados - 1999-1930 
A Figura 10 mostra-nos tais trajetórias. Continuando como está, Pelotas perderá espaço na economia gaúcha; convergindo para a taxa estadual, sua participação manter-se-á constante; e, absorvendo o crescimento de Rio Grande, a economia pelotense seguirá uma trajetória de grande crescimento.

\subsection{Tendências e cenários para o PIB real per capita}

Na Tabela 5, são apresentadas as taxas de crescimento do PIB real per capita de Pelotas, de Rio Grande e do Rio Grande do Sul, calculadas com base nas observações de tal indicador entre 1999-2009. Três cenários também são projetados para o desenvolvimento do PIB real per capita de Pelotas.

O PIB real per capita de Pelotas é o mais baixo entre os principais municípios do interior do estado. Com a taxa de crescimento anual dessa variável sendo de 0,38\% nos últimos anos, se Pelotas continuar nesse ritmo de crescimento, chegará ao ano de 2020 com um PIB real per capita de $R \$ 5.907,90$ e, em 2030, com $R \$$ 6.133,64. Mantendo essa taxa de crescimento, o município levará aproximadamente 184 anos para dobrar o valor de tal indicador.

Tabela 5. Projeções e cenários para o PIB real per capita de Pelotas em R\$ de 2000 - 2020-2030

\begin{tabular}{l|r|r|r|r}
\hline \multirow{2}{*}{ Discriminação } & \multirow{2}{*}{$\begin{array}{c}\text { Taxa de cresci- } \\
\text { mento geomé- } \\
\text { trica }(r)\end{array}$} & $\begin{array}{c}\text { Último PIB per capita } \\
\text { observado }\left(Y_{2009}\right)\end{array}$ & \multicolumn{2}{|c}{ PIB per capita estimado } \\
\cline { 3 - 5 } & $0,38 \%$ & 2009 & 2020 & \multicolumn{2}{|c}{2030} \\
\hline Pelotas atual & $2,17 \%$ & $5.669,18$ & $5.907,90$ & $6.133,64$ \\
Pelotas = Rio Grande do Sul & $4,66 \%$ & $5.669,18$ & $7.176,50$ & $8.891,95$ \\
Pelotas = Rio Grande & $4,66 \%$ & $5.669,18$ & $9.360,85$ & $14.767,64$ \\
Rio Grande & $2,17 \%$ & $15.449,07$ & $25.509,26$ & $40.243,30$ \\
Rio Grande do Sul & & $9.786,01$ & $12.387,92$ & $15.349,08$ \\
\hline
\end{tabular}

Fonte: cálculos dos autores.

Rio Grande, com uma taxa de crescimento calculada em $4,66 \%$, chegará a 2020 com um PIB real per capita de $\mathrm{R} \$ 25.509,26$ e, em 2030, com $\mathrm{R} \$ 40.243,30$, valores altamente superiores em relação a Pelotas. Se mantiver essa expressiva taxa de crescimento, dobrará seu indicador em 15 anos.

Por fim, com uma taxa de crescimento de $2,17 \%$, o estado alcançará, em 2020, um valor de $\mathrm{R} \$ 12.387,92$ e, em 2030 , um valor de $\mathrm{R} \$ 15.349,08$, dobrando seu PIB per capita em aproximadamente 32 anos se mantiver essa taxa de crescimento. 
Na Figura 11, percebe-se que o PIB real per capita de Pelotas mantém-se praticamente estagnado durante o período. Com trajetórias diferentes, o Rio Grande do Sul e o município de Rio Grande apresentam tendências de aumento, com destaque para o último, que se distancia de Pelotas de forma acelerada.

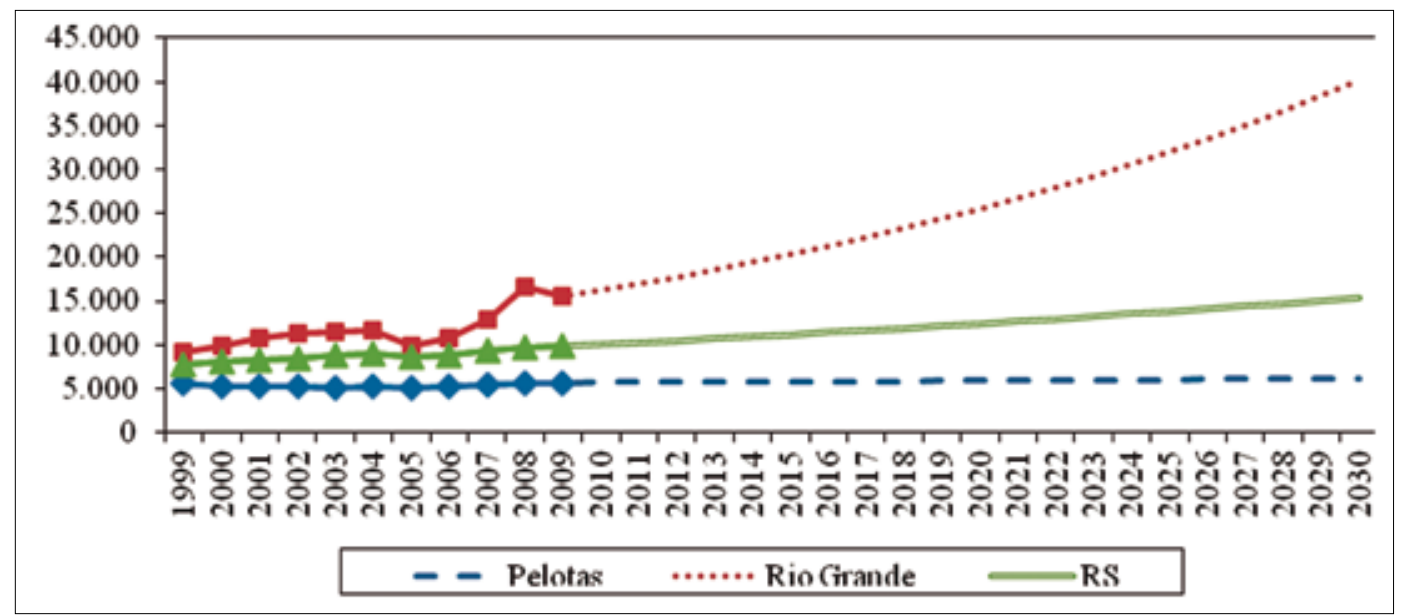

Fonte: cálculos dos autores.

Figura 11. Trajetória das projeções para o PIB real per capita de Pelotas, Rio Grande e RS em R\$ de 2000 - 1999-1930

O último PIB real per capita de Pelotas observado foi em 2009 e atingiu um valor de $\mathrm{R} \$ 5.669,18$. Contando com a igualdade entre a taxa de crescimento de Pelotas e do Rio Grande do Sul, em 2030, seu PIB real per capita será de $\mathrm{R} \$ 8.891,95$. Já, se considerarmos que o município beneficiar-se-á pelo expressivo crescimento apresentado por Rio Grande, com suas taxas de crescimento igualando-se, o PIB real per capita de Pelotas, em 2030, será de $\mathrm{R} \$ 14.767,64$, um valor 2,6 vezes maior que o último observado no município em 2009.

Atentando-se para a Figura 12 percebe-se que, mantendo o crescimento atual, o PIB real per capita de Pelotas será praticamente constante. Com sua taxa de crescimento sendo igual à estadual, seus valores aumentarão consideravelmente. Por fim, a dinâmica de crescimento do PIB real per capita de Pelotas será extremamente positiva se sua taxa de crescimento aproximar-se da taxa de Rio Grande. 


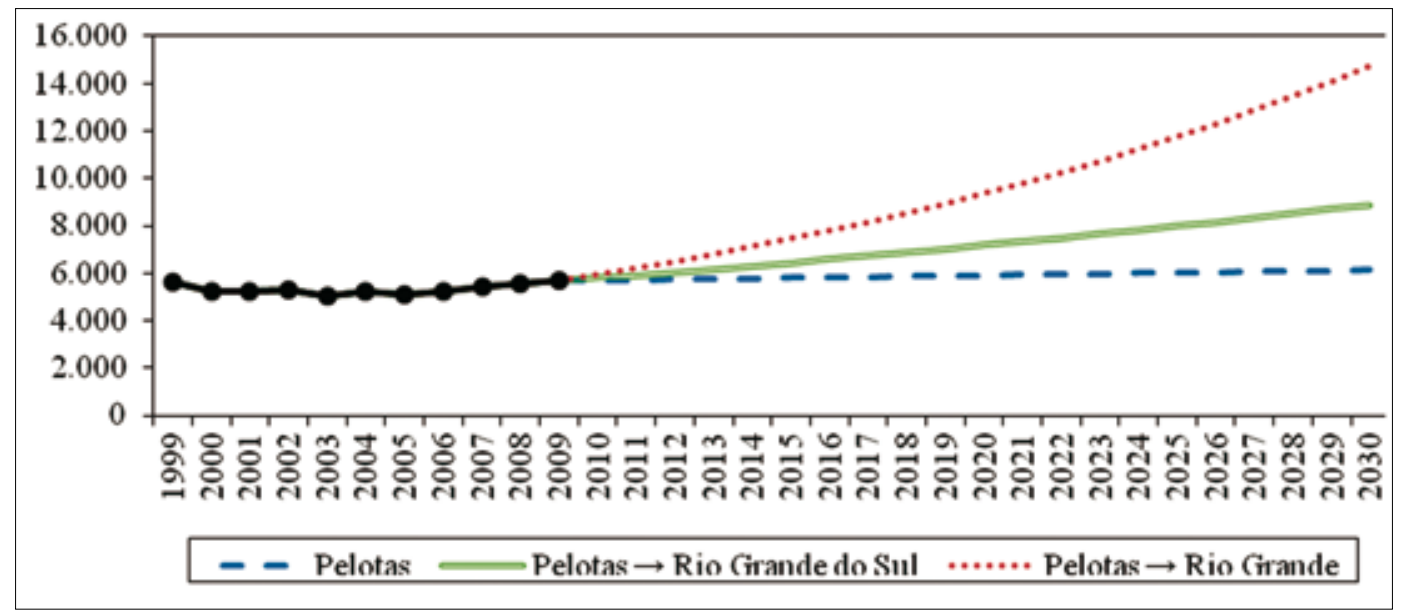

Fonte: cálculos dos autores.

Figura 12. Trajetória do PIB real per capita de Pelotas para os cenários projetados em $\mathrm{R} \$$ de 2000 - 1999-1930

\section{Considerações finais}

Este trabalho apresentou uma análise do desempenho econômico de Pelotas no período de 1939 a 2009, abrangendo 71 anos de estudo. Os dados comprovam que o crescimento econômico do município de Pelotas não acompanhou a trajetória de crescimento dos principais municípios do interior do estado do Rio Grande do Sul e sua importância econômica decresceu. A metade Sul, que no início do século XX era de elevada importância econômica para o estado, com Pelotas e Rio Grande como municípios principais, foi perdendo força, com grande parcela desse declínio representada pelo desempenho do primeiro.

Em termos de importância relativa no PIB real estadual, a participação do município caiu gradativamente ao longo dos anos, principalmente a partir da segunda metade do século passado. Enquanto isso, alguns municípios do interior percorreram o caminho inverso, aumentando sua relevância econômica no Rio Grande do Sul. Seu vizinho, Rio Grande, também apresentou queda na participação relativa, mas apresentou uma tendência ascendente a partir de meados da década de 1990 .

Em relação ao PIB real per capita, o caminho percorrido por Pelotas mostrou-se ainda mais negativo. Em 1939, esse indicador do município foi praticamente o dobro do apresentado no estado, ficando entre os municípios que possuíam os melhores valores no Rio Grande do Sul. Porém, seu crescimento foi o mais baixo entre 
os municípios estudados, compreendendo o período de 1939 até 2009, fechando a série com o menor valor de PIB real per capita dentre os tais.

Num contexto regional, analisado pela comparação de Pelotas com o Corede Sul, percebe-se que sua importância também foi diminuindo em termos de participação relativa no PIB real da região. Seguindo uma trajetória contrária, Rio Grande viu sua importância regional em ascendência. Seu PIB real, ao final da série, representou quase a metade do PIB real do Corede Sul, enquanto Pelotas teve uma parcela de apenas $27,61 \%$, tendo em vista que a população do município representou, em 2009, 39\% da população total do Corede Sul.

As projeções realizadas revelam que o futuro da economia de Pelotas não será muito promissor se forem mantidas as trajetórias atuais de crescimento. Um cenário possível é a tendência do município de ser beneficiado pelo alto crescimento de Rio Grande, o que colocará a economia de Pelotas em um caminho de grande crescimento econômico.

Desenvolvemos uma análise descritiva e quantitativa do baixo dinamismo econômico apresentado por Pelotas durante o período estudado. Os motivos que levaram à essa baixa evolução do município em relação a Rio Grande e também a outros municípios do interior do estado, bem como a evolução de seus indicadores sociais, são assuntos a serem desenvolvidos em pesquisas posteriores. 


\title{
The economic performance of Pelotas (1939-2009): a comparative analysis with major cities of interior RS
}

\begin{abstract}
This paper aims to analyze the economic performance between the years of 1939 and 2009 in Pelotas city, one of most important Rio Grande do Sul's economic strength in the 19th and the early 20th Century. This analysis is made by comparing the performance obtained by its economic aspects to the main cities of the state and Rio Grande do Sul's own economic history. The data show that the Pelotas economy did not evolve in order to follow the growth of the major cities of the state as a whole. Moreover, Pelotas, differently from its neighbor city, Rio Grande, presented another performance, remaining among economic strengths of Rio Grande do Sul and showing trends of great economic advancement, especially in the early 90 s. Some projections were made based on economic growth of Pelotas. Keeping the current trajectory, the Pelotas will continue losing ground in the economy of the state and its evolution with low GDP per capita.
\end{abstract}

Keywords: Economic growth. GDP. GDP per capita. Pelotas.

\section{El desempeño económico de Pelotas (1939-2009): un análisis comparativo con ciudades principales de interior $\mathrm{RS}$}

\section{Resumen}

Este estudio tiene como objetivo analizar el desempeño económico entre los años 1939 y 2009 de la ciudad de Pelotas, una de las principales fuerzas económicas Del Rio Grande do Sul, en los siglos XIX y XX. El análisis es realizado mediante la comparación de las trayectorias recorridas por algunas de sus variables económicas, con las principales ciudades del estado y de la trayectoria recorrida por el Río Grande do Sul. Los datos muestran que la economía de Pelotas no se desarrolló acompañando el camino seguido por las principales ciudades del interior y del Estado en su conjunto. Por otra parte, Pelotas vio su vecino, Rio Grande, mantenerse como una de las fuerzas económicas del estado y mostrar un mayor crecimiento económico, sobre todo a partir de los años 90. Fueron realizadas algunas proyecciones basadas en el reciente crecimiento económico de Pelotas. Manteniendo la trayectoria actual, el municipio continuará perdiendo terreno dentro de la economía del estado y teniendo baja evolución de su PIB per cápita.

Palabras clave: Crecimiento económico. PIB. PIB per cápita. Pelotas. 


\section{Notas}

1 Para o cálculo do PIB regional foi utilizada a classificação do Conselho Regional de Desenvolvimento da Região Sul (Corede Sul).

2 Destacando-se pesquisas desenvolvidas para o município de Passo Fundo, Montoya (2005, 2010).

3 Dados disponíveis no site: http://www.ipeadata.gov.br.

4 O PIB a preços de mercado é o valor monetário de venda dos produtos finais produzidos dentro de uma determinada região em determinado período de tempo. Já o PIB a custo de fatores corresponde ao PIB a preços de mercado menos os impostos indiretos mais os subsídios concedidos.

5 Foram considerados municípios do interior do estado todos aqueles que não fazem parte da região Metropolitana de Porto Alegre (RMPA).

6 Procurou-se montar uma série, aproximadamente, de 10 em 10 anos, mas isso não foi possível pela indisponibilidade de dados. Para evitar um intervalo demasiadamente grande na série, foram incluídos os anos de 1985 e 1996, pela falta de dados para 1990.

7 O ranking em nível estadual encontra-se entre parênteses.

8 Em razão da indisponibilidade de dados anuais para o PIB municipal, para o cálculo da taxa de crescimento médio entre dois períodos, utilizou-se a fórmula da taxa geométrica de crescimento anual.

$9 \quad$ Embora seja um índice muito útil, por se tratar de uma média, esconde várias disparidades na distribuição de renda. Por esse motivo, é preciso ter cuidado ao analisá-lo como indicador de desenvolvimento de uma economia. Existem outros indicadores para esse objetivo, como o IDH. Como não se obtém dados desse índice para todo o período estudado, optou-se por utilizar o PIB real per capita.

10 Até o ano de 1996, o conceito utilizado para o cálculo do PIB foi o de custo de fatores. As estimativas do PIB a custo de fatores correspondem à soma dos setores: agropecuária (AGR), indústria (IND) e serviços (SER). A partir de 1999, o conceito do PIB utilizado é o de preços de mercado. Nesse caso, devem ser acrescentados os impostos sobre produtos (IMP).

11 Os Coredes foram criados em 1994 e subdividem o estado em 28 regiões com o objetivo de promover um fórum de discussão e decisão a respeito de políticas e ações que visam ao desenvolvimento regional. Municípios que compõem o Corede Sul: Amaral Ferrador, Arroio do Padre, Arroio Grande, Canguçu, Capão do Leão, Cerrito, Chuí, Herval, Jaguarão, Morro Redondo, Pedras Altas, Pedro Osório, Pelotas, Pinheiro Machado, Piratini, Rio Grande, Santa Vitória do Palmar, Santana da Boa Vista, São José do Norte, São Lourenço do Sul, Tavares e Turuçu.

12 Anteriormente, isso não era possível, pois somente a partir de 1999 o conceito utilizado para o cálculo do PIB passou a ser o de preços de mercado, abrangendo além dos três setores principais, os impostos sobre produtos.

13 Para mais detalhes, ver Gujarati e Porter (2011).

\section{Referências}

ALONSO, José Antonio Fialho. Evolução das desigualdades inter-regionais de renda interna no Rio Grande do Sul 1939-70. Porto Alegre, FEE, 1986. Disponível em: <http://cdn.fee.tche.br/ teses/digitalizacao/teses_9.pdf>. Acesso em: 14 jul. 2012.

CORONEL, Daniel Arruda; AMARAL, Fabiano Dutra; SILVA, Mariangela Amaral e. Notas sobre o processo de desenvolvimento da metade Sul e Norte do estado do Rio Grande do Sul: uma abordagem comparativa. Perspectiva Econômica, São Leopoldo, v.3, n.2, p. 27-43, jul./dez. 2007. Disponível em: <http://www.perspectivaeconomica.unisinos.br/pdfs/68.pdf>. Acesso em: 02 jul. 2012.

FRIEDRICH, Delnei Nunes. Análise do emprego setorial no Rio Grande do Sul baseado no modelo insumo-produto. 2002. 120 f. Dissertação (Mestrado em Economia) - Universidade Federal do Rio Grande do Sul, Programa de Pós-Graduação em Economia. Disponível em: <http://www.lume. ufrgs.br/bitstream/handle/10183/4264/000349180.pdf?sequence=1>. Acesso em: 16 abr. 2012. 
GUJARATI, Damodar N.; PORTER, Dawn C. Econometria básica. 5. ed. Porto Alegre: AMGM, 2011. $924 \mathrm{p}$.

ILHA, Adayr da Silva; ALVES, Fabiano Dutra; SARAVIA, Luis Hector Barboza. Desigualdades regionais no Rio Grande do Sul: o caso da metade Sul. In: ENCONTRO DE ECONOMIA GAÚCHA, 1, 2002, Porto Alegre. Anais... Porto Alegre: FEE, 2002. Disponível em: <http://www.fee. tche.br/sitefee/download/eeg/1/mesa_3_ilha_alves_saravia.pdf>. Acesso em: 13 mai. 2012.

MENEZES, Gabrielito; FEIJÓ, Flavio Tosi. O contraste econômico entre as metades Sul e Norte do Rio Grande do Sul: uma aplicação do modelo da base econômica. In: ENCONTRO DE ECONOMIA GAÚCHA, 4, 2008, Porto Alegre. Anais... Porto Alegre: FEE, 2008. Disponível em: <http://www.fee.tche.br/4-encontro-economia-gaucha/trabalhos/localizacao-sessao5-3.doc>. Acesso em: 26 mai. 2012.

MONASTERIO, Leonardo M.; ZELL, Davi Coswig. Uma estimativa de renda per capita municipal na província de São Pedro do Rio Grande do Sul em 1872. 2004. Disponível em: <http://ich. ufpel.edu.br/economia/arquivos/monasteriozell2004.pdf>. Acesso em: 20 ago. 2012.

. O Rio Grande do Sul em 1872: análise setorial da ocupação dos municípios. In: ENCONTRO DE ECONOMIA GAÚCHA, 2, 2004, Porto Alegre. Anais... Porto Alegre: FEE, 2004. Disponível em: <http://www.fee.tche.br/sitefee/download/eeg/2/3.1.zip>. Acesso em: 23 ago. 2012.

MONTOYA, Marco Antonio; FINAMORE, Eduardo Belisário. A trajetória do crescimento econômico do município de Passo Fundo, no período de 1991 a 2002. Passo Fundo, 2005. Texto para discussão, n. 18. Disponível em: <http://www.upf.br/cepeac/download/td_18_2005.pdf>. Acesso em: 17 abr. 2012.

MONTOYA, Marco Antonio; PASQUAL, Cássia Aparecida; FINAMORE, Eduardo Belisário; OLIVEIRA, Guilherme de. Mudança setorial e a nova dinâmica do crescimento econômico do município de Passo Fundo. Teoria e Evidência Econômica, Passo Fundo: FEA, UPF, ano 16, n. 34, p. 30-41, jan./jun. 2010. Disponível em: <http://www.upf.br/cepeac/download/Revista\%20 TEE_ano15_n34_2010.pdf>. Acesso em: 15 abr. 2012.

MORAES, Roberto Camps. Metade Sul vs metade Norte: uma comparação a partir de dados municipais do Rio Grande do Sul. 2006. In: ENCONTRO DE ECONOMIA GAÚCHA, 3, 2006, Porto Alegre. Anais... Porto Alegre: FEE, 2006. Disponível em: <http://www.fee.tche.br/3eeg/Artigos/ m23t05.pdf>. Acesso em: 08 jun. 2012. 


\section{Apêndice A - Tabelas}

Tabela A1. PIB real em R $\$$ de 2000 (milhões), participação relativa no PIB real do RS e ranking 1939-2009

\begin{tabular}{|c|c|c|c|c|c|c|c|c|c|c|c|c|c|c|c|}
\hline \multirow{2}{*}{ Discriminação } & \multicolumn{3}{|c|}{1939} & \multicolumn{3}{|c|}{1949} & \multicolumn{3}{|c|}{1959} & \multicolumn{3}{|c|}{1970} & \multicolumn{3}{|c|}{1980} \\
\hline & PIB & $\%$ & Ranking & PIB & $\%$ & Ranking & PIB & $\%$ & Ranking & PIB & $\%$ & Ranking & PIB & $\%$ & Ranking \\
\hline Bento Gonçalves & 22,79 & 0,50 & $10^{\circ}\left(58^{\circ}\right)$ & 62,46 & 0,86 & $10^{\circ}\left(33^{\circ}\right)$ & 96,42 & 0,73 & $10^{\circ}\left(31^{\circ}\right)$ & 231,90 & 0,87 & $8^{\circ}\left(21^{\circ}\right)$ & 768,63 & 1,26 & $7^{\circ}\left(12^{\circ}\right)$ \\
\hline Caxias do Sul & 71,06 & 1,55 & $7^{\circ}\left(13^{\circ}\right)$ & 191,96 & 2,63 & $4^{0}\left(6^{\circ}\right)$ & 301,80 & 2,29 & $3^{\circ}\left(5^{\circ}\right)$ & 908,55 & 3,41 & $1^{\circ}\left(3^{\circ}\right)$ & $2.423,79$ & 3,98 & $1^{\circ}\left(3^{\circ}\right)$ \\
\hline Erechim & 83,30 & 1,81 & $4^{0}\left(8^{\circ}\right)$ & 209,17 & 2,87 & $2^{\circ}\left(3^{\circ}\right)$ & 203,36 & 1,54 & $7^{\circ}\left(10^{\circ}\right)$ & 220,96 & 0,83 & $10^{\circ}\left(24^{\circ}\right)$ & 411,59 & 0,68 & $10^{\circ}\left(28^{\circ}\right)$ \\
\hline Lajeado & 43,86 & 0,96 & $9^{\circ}\left(30^{\circ}\right)$ & 70,83 & 0,97 & $9^{\circ}\left(29^{\circ}\right)$ & 105,26 & 0,80 & $9^{\circ}\left(25^{\circ}\right)$ & 229,85 & 0,86 & $9^{\circ}\left(22^{\circ}\right)$ & 429,36 & 0,70 & $9^{\circ}\left(22^{\circ}\right)$ \\
\hline Passo Fundo & 73,31 & 1,60 & $6^{\circ}\left(11^{\circ}\right)$ & 147,24 & 2,02 & $7^{\circ}\left(10^{\circ}\right)$ & 212,01 & 1,61 & $6^{\circ}\left(9^{\circ}\right)$ & 350,15 & 1,31 & $6^{\circ}\left(11^{\circ}\right)$ & 944,75 & 1,55 & $5^{\circ}\left(9^{\circ}\right)$ \\
\hline Pelotas & 259,69 & 5,66 & $1^{\circ}\left(2^{\circ}\right)$ & 304,17 & 4,17 & $1^{\circ}\left(2^{\circ}\right)$ & 679,01 & 5,14 & $1^{\circ}\left(2^{\circ}\right)$ & 856,26 & 3,21 & $2^{\circ}\left(4^{\circ}\right)$ & $1.689,66$ & 2,77 & $3^{\circ}\left(5^{\circ}\right)$ \\
\hline Rio Grande & 217,91 & 4,75 & $2^{\circ}\left(3^{\circ}\right)$ & 205,49 & 2,81 & $3^{\circ}\left(5^{\circ}\right)$ & 476,00 & 3,60 & $2^{\circ}\left(3^{\circ}\right)$ & 500,74 & 1,88 & $3^{\circ}\left(6^{\circ}\right)$ & $1.724,16$ & 2,83 & $2^{\circ}\left(4^{\circ}\right)$ \\
\hline Santa Cruz do Sul & 80,88 & 1,76 & $5^{\circ}\left(9^{\circ}\right)$ & 191,30 & 2,62 & $5^{\circ}\left(7^{\circ}\right)$ & 244,10 & 1,85 & $4^{\circ}\left(6^{\circ}\right)$ & 380,54 & 1,43 & $5^{\circ}\left(9^{\circ}\right)$ & 864,94 & 1,42 & $6^{\circ}\left(10^{\circ}\right)$ \\
\hline Santa Maria & 104,37 & 2,27 & $3^{\circ}\left(6^{\circ}\right)$ & 148,79 & 2,04 & $6^{\circ}\left(9^{\circ}\right)$ & 241,98 & 1,83 & $5^{\circ}\left(7^{\circ}\right)$ & 494,58 & 1,86 & $4^{\circ}\left(7^{\circ}\right)$ & 966,71 & 1,59 & $4^{\circ}\left(8^{\circ}\right)$ \\
\hline Uruguaiana & 70,65 & 1,54 & $8^{\circ}\left(14^{\circ}\right)$ & 98,81 & 1,35 & $8^{\circ}\left(18^{\circ}\right)$ & 152,90 & 1,16 & $8^{\circ}\left(15^{\circ}\right)$ & 317,10 & 1,19 & $7^{\circ}\left(13^{\circ}\right)$ & 702,55 & 1,15 & $8^{\circ}\left(14^{\circ}\right)$ \\
\hline Porto Alegre & $1.002,89$ & 21,85 & - & $1.613,93$ & 22,11 & - & $3.122,20$ & 23,64 & - & 7.024,68 & 26,36 & - & $14.985,17$ & 24,60 & - \\
\hline Rio Grande do Sul & $4.590,21$ & 100 & - & $7.300,09$ & 100 & & $13.206,66$ & 100 & - & $26.644,81$ & 100 & 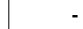 & $60.926,93$ & 100 & - \\
\hline
\end{tabular}

\begin{tabular}{|c|c|c|c|c|c|c|c|c|c|c|c|c|}
\hline \multirow{2}{*}{ Discriminação } & \multicolumn{3}{|c|}{1985} & \multicolumn{3}{|c|}{1996} & \multicolumn{3}{|c|}{2000} & \multicolumn{3}{|c|}{2009} \\
\hline & PIB & $\%$ & Ranking & PIB & $\%$ & Ranking & PIB & $\%$ & Ranking & PIB & $\%$ & Ranking \\
\hline Bento Gonçalves & 846,46 & 1,25 & $7^{\circ}\left(14^{\circ}\right)$ & 938,64 & 1,27 & $7^{\circ}\left(13^{\circ}\right)$ & $1.129,44$ & 1,38 & $7^{\circ}\left(13^{\circ}\right)$ & $1.251,27$ & 1,20 & $7^{\circ}\left(14^{\circ}\right)$ \\
\hline Caxias do Sul & $3.219,07$ & 4,74 & $1^{\circ}\left(2^{\circ}\right)$ & $3.647,26$ & 4,93 & $1^{\circ}\left(2^{\circ}\right)$ & $4.342,50$ & 5,31 & $1^{\circ}\left(3^{\circ}\right)$ & $6.041,06$ & 5,80 & $1^{\circ}\left(3^{\circ}\right)$ \\
\hline Erechim & 504,89 & 0,74 & $9^{\circ}\left(24^{\circ}\right)$ & 711,73 & 0,96 & $8^{\circ}\left(16^{\circ}\right)$ & 777,05 & 0,95 & $8^{\circ}\left(17^{\circ}\right)$ & $1.014,05$ & 0,97 & $9^{\circ}\left(17^{\circ}\right)$ \\
\hline Lajeado & 390,63 & 0,58 & $10^{\circ}\left(35^{\circ}\right)$ & 563,31 & 0,76 & $10^{\circ}\left(19^{\circ}\right)$ & 623,55 & 0,76 & $10^{\circ}\left(22^{\circ}\right)$ & 874,11 & 0,84 & $10^{\circ}\left(20^{\circ}\right)$ \\
\hline Passo Fundo & 831,32 & 1,23 & $8^{\circ}\left(15^{\circ}\right)$ & $1.033,27$ & 1,40 & $5^{\circ}\left(11^{\circ}\right)$ & $1.436,42$ & 1,76 & $4^{\circ}\left(9^{\circ}\right)$ & $1.800,78$ & 1,73 & $5^{\circ}\left(10^{\circ}\right)$ \\
\hline Pelotas & $1.666,82$ & 2,46 & $2^{\circ}\left(5^{\circ}\right)$ & $1.730,96$ & 2,34 & $2^{\circ}\left(5^{\circ}\right)$ & $1.682,79$ & 2,06 & $3^{\circ}\left(7^{\circ}\right)$ & $1.858,22$ & 1,78 & $4^{\circ}\left(9^{\circ}\right)$ \\
\hline Rio Grande & $1.525,44$ & 2,25 & $3^{\circ}\left(6^{\circ}\right)$ & $1.192,08$ & 1,61 & $4^{\circ}\left(10^{\circ}\right)$ & $1.850,18$ & 2,26 & $2^{\circ}\left(6^{\circ}\right)$ & $3.033,12$ & 2,91 & $2^{\circ}\left(4^{\circ}\right)$ \\
\hline Santa Cruz do Sul & $1.184,16$ & 1,75 & $4^{\circ}\left(9^{\circ}\right)$ & 949,38 & 1,28 & $6^{\circ}\left(12^{\circ}\right)$ & $1.408,95$ & 1,72 & $5^{\circ}\left(10^{\circ}\right)$ & $2.114,66$ & 2,03 & $3^{\circ}\left(8^{\circ}\right)$ \\
\hline Santa Maria & $1.096,45$ & 1,62 & $5^{\circ}\left(11^{\circ}\right)$ & $1.447,63$ & 1,96 & $3^{\circ}\left(7^{\circ}\right)$ & $1.319,43$ & 1,61 & $6^{\circ}\left(12^{\circ}\right)$ & $1.669,72$ & 1,60 & $6^{\circ}\left(11^{\circ}\right)$ \\
\hline Uruguaiana & 848,31 & 1,25 & $6^{\circ}\left(13^{\circ}\right)$ & 668,87 & 0,90 & $9^{\circ}\left(17^{\circ}\right)$ & 706,58 & 0,86 & $9^{\circ}\left(19^{\circ}\right)$ & $1.105,35$ & 1,06 & $8^{\circ}\left(15^{\circ}\right)$ \\
\hline Porto Alegre & $14.529,10$ & 21,41 & - & $20.218,22$ & 27,31 & - & $16.510,64$ & 20,18 & - & $18.248,33$ & 17,51 & - \\
\hline Rio Grande do Sul & $67.858,85$ & 100 & - & $74.032,83$ & 100 & - & $81.814,71$ & 100 & - & $104.243,77$ & 100 & - \\
\hline
\end{tabular}

Fonte: elaborada com base nos dados do IPEADATA. 
Tabela A2. Evolução da participação relativa do PIB real setorial no PIB real total - 1939-2009

\begin{tabular}{|c|c|c|c|c|c|c|c|c|c|c|c|c|c|c|c|c|c|c|c|c|c|}
\hline \multirow{2}{*}{ Discriminação } & \multicolumn{3}{|c|}{1939} & \multicolumn{3}{|c|}{1949} & \multicolumn{3}{|c|}{1959} & \multicolumn{3}{|c|}{1970} & \multicolumn{3}{|c|}{1980} & \multicolumn{3}{|c|}{1985} & \multicolumn{3}{|c|}{1996} \\
\hline & AGR & IND & SER & AGR & IND & SER & AGR & IND & SER & AGR & IND & SER & AGR & IND & SER & AGR & IND & SER & AGR & IND & SER \\
\hline BentoGonçalves & 26,28 & 30,39 & 43,33 & 14,40 & 33,98 & 51,63 & 10,23 & 43,43 & 46,34 & 14,32 & 50,00 & 35,68 & 7,53 & 63,91 & 28,56 & 6,10 & 57,23 & 36,67 & 4,65 & 56,64 & 38,71 \\
\hline Caxias do Sul & 9,32 & 46,86 & 43,83 & 7,20 & 40,29 & 52,51 & 7,00 & 55,36 & 37,64 & 6,41 & 48,39 & 45,20 & 3,03 & 56,43 & 40,54 & 2,09 & 52,96 & 44,95 & 2,76 & 55,54 & 41,70 \\
\hline Erechim & 52,77 & 15,03 & 32,20 & 41,21 & 13,59 & 45,19 & 23,72 & 15,76 & 60,52 & 13,57 & 29,12 & 57,30 & 13,38 & 33,35 & 53,27 & 12,84 & 25,87 & 61,29 & 7,16 & 46,40 & 46,44 \\
\hline Lajeado & 61,25 & 10,45 & 28,31 & 50,64 & 11,35 & 38,01 & 45,31 & 22,59 & 32,11 & 29,70 & 22,19 & 48,11 & 20,41 & 40,49 & 39,10 & 22,11 & 28,86 & 49,03 & 7,21 & 52,68 & 40,12 \\
\hline Passo Fundo & 31,85 & 20,13 & 48,01 & 30,74 & 21,86 & 47,40 & 23,19 & 24,13 & 52,69 & 18,19 & 25,00 & 56,81 & 10,60 & 45,19 & 44,21 & 14,05 & 29,08 & 56,87 & 5,24 & 25,22 & 69,54 \\
\hline Pelotas & 21,59 & 17,52 & 60,89 & 19,31 & 29,36 & 51,34 & 9,88 & 29,81 & 60,31 & 9,56 & 31,30 & 59,14 & 6,43 & 44,79 & 48,78 & 5,29 & 43,36 & 51,35 & 4,59 & 24,75 & 70,66 \\
\hline Rio Grande & 3,61 & 34,81 & 61,58 & 8,48 & 46,62 & 44,90 & 3,36 & 63,07 & 33,57 & 5,08 & 42,02 & 52,90 & 3,78 & 59,34 & 36,88 & 4,80 & 31,74 & 63,46 & 3,21 & 30,98 & 65,81 \\
\hline $\begin{array}{l}\text { Santa Cruz } \\
\text { do Sul }\end{array}$ & 48,18 & 17,96 & 33,87 & 29,58 & 18,49 & 51,92 & 30,32 & 26,58 & 43,10 & 37,29 & 25,85 & 36,86 & 12,47 & 57,43 & 30,09 & 10,49 & 53,17 & 36,34 & 7,38 & 51,02 & 41,60 \\
\hline Santa Maria & 20,07 & 8,37 & 71,56 & 18,69 & 10,42 & 70,90 & 12,12 & 12,61 & 75,27 & 9,68 & 16,82 & 73,50 & 10,83 & 20,81 & 68,36 & 8,81 & 16,42 & 74,76 & 4,74 & 13,30 & 81,97 \\
\hline Uruguaiana & 17,74 & 14,46 & 67,80 & 29,56 & 10,25 & 60,19 & 27,39 & 11,40 & 61,21 & 25,47 & 11,62 & 62,91 & 29,41 & 16,16 & 54,43 & 30,34 & 19,76 & 49,90 & 27,57 & 8,79 & 63,63 \\
\hline Porto Alegre & 0,77 & 21,25 & 77,98 & 0,41 & 24,82 & 74,77 & 0,08 & 29,98 & 69,94 & 0,16 & 29,01 & 70,82 & 0,23 & 30,83 & 68,93 & 0,25 & 23,62 & 76,13 & 0,06 & 18,31 & 81,63 \\
\hline $\begin{array}{l}\text { Rio Grande } \\
\text { do Sul }\end{array}$ & 34,31 & 16,61 & 49,08 & 30,15 & 21,22 & 48,64 & 23,89 & 26,94 & 49,17 & 21,39 & 28,26 & 50,35 & 16,02 & 37,94 & 46,03 & 15,41 & 35,47 & 49,12 & 12,21 & 33,25 & 54,54 \\
\hline
\end{tabular}

\begin{tabular}{l|r|r|r|r|r|r|r|r}
\hline \multirow{2}{*}{ Discriminação } & \multicolumn{3}{|c|}{2000} & \multicolumn{4}{|c}{2009} \\
\cline { 2 - 9 } & \multicolumn{1}{|c|}{ AGR } & \multicolumn{1}{c|}{ IND } & \multicolumn{1}{c|}{ SER } & \multicolumn{1}{c|}{ IMP } & \multicolumn{1}{c}{ AGR } & \multicolumn{1}{c}{ IND } & \multicolumn{1}{c}{ SER } & \multicolumn{1}{l}{ IMP } \\
\hline Bento Gonçalves & 2,28 & 38,13 & 45,51 & 14,08 & 2,37 & 33,04 & 49,73 & 14,86 \\
Caxias do Sul & 1,78 & 34,08 & 50,01 & 14,14 & 1,39 & 36,32 & 47,64 & 14,65 \\
Erechim & 3,66 & 27,28 & 57,45 & 11,61 & 1,76 & 35,39 & 52,21 & 10,65 \\
Lajeado & 1,99 & 34,19 & 50,70 & 13,12 & 0,77 & 31,50 & 54,95 & 12,78 \\
Passo Fundo & 2,19 & 16,64 & 69,73 & 11,44 & 2,03 & 19,49 & 68,24 & 10,24 \\
Pelotas & 2,63 & 19,17 & 68,46 & 9,74 & 3,62 & 18,00 & 69,97 & 8,42 \\
Rio Grande & 2,01 & 30,91 & 51,35 & 15,73 & 2,15 & 29,15 & 44,30 & 24,40 \\
Santa Cruz do Sul & 3,34 & 38,64 & 39,41 & 18,61 & 2,65 & 41,90 & 37,72 & 17,73 \\
Santa Maria & 2,45 & 12,96 & 74,27 & 10,32 & 3,01 & 14,32 & 73,79 & 8,89 \\
Uruguaiana & 9,78 & 19,55 & 61,54 & 9,13 & 13,49 & 9,80 & 38,38 & 38,33 \\
Porto Alegre & 0,05 & 12,75 & 71,78 & 15,43 & 0,06 & 12,31 & 71,18 & 16,45 \\
Rio Grande do Sul & 7,31 & 26,20 & 54,34 & 12,15 & 8,63 & 25,56 & 53,32 & 12,49 \\
\hline
\end{tabular}

Fonte: elaborada com base nos dados do IPEADATA. 
Tabela A3. PIB real em R\$ de 2000 (milhões), participação relativa no PIB real do RS, participação relativa de Pelotas no Corede Sul e ranking - 1999-2009

\begin{tabular}{|c|c|c|c|c|c|c|c|c|c|c|c|c|c|c|c|c|c|c|}
\hline \multirow{2}{*}{ Discriminação } & \multicolumn{3}{|c|}{1999} & \multicolumn{3}{|c|}{2000} & \multicolumn{3}{|c|}{2001} & \multicolumn{3}{|c|}{2002} & \multicolumn{3}{|c|}{2003} & \multicolumn{3}{|c|}{2004} \\
\hline & PIB & $\%$ & Rank. & PIB & $\%$ & Rank. & PIB & $\%$ & Rank. & PIB & $\%$ & Rank. & PIB & $\%$ & Rank. & PIB & $\%$ & Rank. \\
\hline Bento Gonçalves & $1.077,62$ & 1,37 & $7^{\circ}\left(13^{\circ}\right)$ & $1.129,44$ & 1,38 & $7^{\circ}\left(13^{\circ}\right)$ & $1.093,54$ & 1,29 & $7^{\circ}\left(13^{\circ}\right)$ & $1.126,15$ & 1,29 & $7^{\circ}\left(13^{\circ}\right)$ & $1.060,81$ & 1,17 & $7^{\circ}\left(14^{\circ}\right)$ & $1.146,36$ & 1,23 & $7^{\circ}\left(14^{\circ}\right)$ \\
\hline Caxias do Sul & $3.960,19$ & 5,04 & $1^{\circ}\left(3^{\circ}\right)$ & $4.342,50$ & 5,31 & $1^{\circ}\left(3^{\circ}\right)$ & $4.406,15$ & 5,20 & $1^{\circ}\left(3^{\circ}\right)$ & $4.537,48$ & 5,18 & $1^{\circ}\left(3^{\circ}\right)$ & $4.619,11$ & 5,08 & $1^{\circ}\left(3^{\circ}\right)$ & $5.054,61$ & 5,43 & $1^{\circ}\left(3^{\circ}\right)$ \\
\hline Erechim & 746,66 & 0,95 & $8^{\circ}\left(17^{\circ}\right)$ & 777,05 & 0,95 & $8^{\circ}\left(17^{\circ}\right)$ & 811,79 & 0,96 & $8^{\circ}\left(17^{\circ}\right)$ & 751,50 & 0,86 & $9^{\circ}\left(19^{\circ}\right)$ & 858,88 & 0,94 & $8^{\circ}\left(17^{\circ}\right)$ & 828,54 & 0,89 & $8^{\circ}\left(17^{\circ}\right)$ \\
\hline Lajeado & 603,72 & 0,77 & $\begin{array}{r}10^{\circ} \\
\left(23^{\circ}\right)\end{array}$ & 623,55 & 0,76 & $10^{\circ}\left(22^{\circ}\right)$ & 597,43 & 0,71 & $10^{\circ}\left(23^{\circ}\right)$ & 642,31 & 0,73 & $10^{\circ}\left(22^{\circ}\right)$ & 681,88 & 0,75 & $10^{\circ}\left(21^{\circ}\right)$ & 749,39 & 0,80 & $10^{\circ}\left(20^{\circ}\right)$ \\
\hline Passo Fundo & $1.334,68$ & 1,70 & $5^{\circ}\left(10^{\circ}\right)$ & $1.436,42$ & 1,76 & $4^{\circ}\left(9^{\circ}\right)$ & $1.373,52$ & 1,62 & $5^{\circ}\left(10^{\circ}\right)$ & $1.528,08$ & 1,75 & $5^{\circ}\left(10^{\circ}\right)$ & $1.623,56$ & 1,79 & $5^{\circ}\left(10^{\circ}\right)$ & $1.596,98$ & 1,71 & $5^{\circ}\left(10^{\circ}\right)$ \\
\hline Pelotas & $1.794,15$ & 2,28 & $2^{\circ}\left(5^{\circ}\right)$ & $1.682,79$ & 2,06 & $3^{\circ}\left(7^{\circ}\right)$ & $1.677,43$ & 1,98 & $3^{\circ}\left(8^{\circ}\right)$ & $1.701,28$ & 1,94 & $3^{\circ}\left(8^{\circ}\right)$ & $1.633,07$ & 1,80 & $4^{\circ}\left(9^{\circ}\right)$ & $1.694,19$ & 1,82 & $4^{\circ}\left(9^{\circ}\right)$ \\
\hline Rio Grande & $1.690,12$ & 2,15 & $3^{\circ}\left(7^{\circ}\right)$ & $1.850,18$ & 2,26 & $2^{\circ}\left(6^{\circ}\right)$ & $2.004,12$ & 2,37 & $2^{\circ}\left(6^{\circ}\right)$ & $2.118,43$ & 2,42 & $2^{\circ}\left(6^{\circ}\right)$ & $2.169,16$ & 2,39 & $2^{\circ}\left(6^{\circ}\right)$ & $2.221,74$ & 2,39 & $2^{\circ}\left(6^{\circ}\right)$ \\
\hline Santa Cruz do Sul & $1.530,78$ & 1,95 & $4^{\circ}\left(8^{\circ}\right)$ & $1.408,95$ & 1,72 & $5^{\circ}\left(10^{\circ}\right)$ & $1.523,25$ & 1,80 & $4^{\circ}\left(9^{\circ}\right)$ & $1.640,08$ & 1,87 & $4^{\circ}\left(9^{\circ}\right)$ & $1.681,29$ & 1,85 & $3^{\circ}\left(8^{\circ}\right)$ & $1.893,76$ & 2,03 & $3^{\circ}\left(8^{\circ}\right)$ \\
\hline Santa Maria & $1.312,96$ & 1,67 & $6^{\circ}\left(11^{\circ}\right)$ & $1.319,43$ & 1,61 & $6^{\circ}\left(12^{\circ}\right)$ & $1.287,67$ & 1,52 & $6^{\circ}\left(12^{\circ}\right)$ & $1.394,35$ & 1,59 & $6^{\circ}\left(11^{\circ}\right)$ & $1.404,28$ & 1,54 & $6^{\circ}\left(11^{\circ}\right)$ & $1.453,84$ & 1,56 & $6^{\circ}\left(11^{\circ}\right)$ \\
\hline Uruguaiana & 742,88 & 0,95 & $9^{\circ}\left(18^{\circ}\right)$ & 706,58 & 0,86 & $9^{\circ}\left(19^{\circ}\right)$ & 786,38 & 0,93 & $9^{\circ}\left(18^{\circ}\right)$ & 846,68 & 0,97 & $8^{\circ}\left(17^{\circ}\right)$ & 762,22 & 0,84 & $9^{\circ}\left(19^{\circ}\right)$ & 820,68 & 0,88 & $9^{\circ}\left(19^{\circ}\right)$ \\
\hline Porto Alegre & $16.551,00$ & 21,06 & - & $16.510,64$ & 20,18 & - & $16.286,04$ & 19,22 & - & $16.925,33$ & 19,33 & - & $15.963,82$ & 17,56 & - & $16.065,95$ & 17,25 & - \\
\hline $\begin{array}{l}\text { Rio Grande } \\
\text { do Sul }\end{array}$ & $78.587,97$ & 100 & - & $81.814,71$ & 100 & - & $84.712,94$ & 100 & - & $87.564,13$ & 100 & - & $90.910,51$ & 100 & - & $93.118,51$ & 100 & - \\
\hline $\begin{array}{l}\text { PIB Corede Sul } \\
\text { e } \% \text { de Pelotas }\end{array}$ & $4.836,74$ & 37,09 & - & $4.872,63$ & 34,54 & - & $5.134,07$ & 32,67 & - & $5.274,70$ & 32,25 & - & $5.347,33$ & 30,54 & - & $5.533,89$ & 30,61 & - \\
\hline
\end{tabular}

\begin{tabular}{|c|c|c|c|c|c|c|c|c|c|c|c|c|c|c|c|}
\hline \multirow{2}{*}{ Discriminação } & \multicolumn{3}{|c|}{2005} & \multicolumn{3}{|c|}{2006} & \multicolumn{3}{|c|}{2007} & \multicolumn{3}{|c|}{2008} & \multicolumn{3}{|c|}{2009} \\
\hline & PIB & $\%$ & Rank. & PIB & $\%$ & Rank. & PIB & $\%$ & Rank. & PIB & $\%$ & Rank. & PIB & $\%$ & Rank. \\
\hline Bento Gonçalves & $1.206,59$ & 1,33 & $7^{\circ}\left(14^{\circ}\right)$ & $1.181,39$ & 1,27 & $7^{\circ}\left(14^{\circ}\right)$ & $1.236,24$ & 1,25 & $7^{\circ}\left(14^{\circ}\right)$ & $1.148,81$ & 1,11 & $8^{\circ}\left(15^{\circ}\right)$ & $1.251,27$ & 1,20 & $7^{\circ}\left(14^{\circ}\right)$ \\
\hline Caxias do Sul & $5.226,71$ & 5,75 & $1^{\circ}\left(3^{\circ}\right)$ & $5.110,03$ & 5,49 & $1^{\circ}\left(3^{\circ}\right)$ & $5.489,31$ & 5,54 & $1^{\circ}\left(3^{\circ}\right)$ & $6.109,99$ & 5,92 & $1^{\circ}\left(3^{\circ}\right)$ & $6.041,06$ & 5,80 & $1^{\circ}\left(3^{\circ}\right)$ \\
\hline Erechim & 821,42 & 0,90 & $9^{\circ}\left(19^{\circ}\right)$ & 835,96 & 0,90 & $9^{\circ}\left(20^{\circ}\right)$ & 949,23 & 0,96 & $9^{\circ}\left(17^{\circ}\right)$ & 978,54 & 0,95 & $9^{\circ}\left(17^{\circ}\right)$ & $1.014,05$ & 0,97 & $9^{\circ}\left(17^{\circ}\right)$ \\
\hline Lajeado & 745,92 & 0,82 & $10^{\circ}\left(21^{\circ}\right)$ & 771,27 & 0,83 & $10^{\circ}\left(21^{\circ}\right)$ & 796,47 & 0,80 & $10^{\circ}\left(21^{\circ}\right)$ & 824,19 & 0,80 & $10^{\circ}(219)$ & 874,11 & 0,84 & $10^{\circ}\left(20^{\circ}\right)$ \\
\hline Passo Fundo & $1.511,69$ & 1,66 & $5^{\circ}\left(10^{\circ}\right)$ & $1.551,30$ & 1,67 & $6^{\circ}\left(11^{\circ}\right)$ & $1.717,82$ & 1,73 & $4^{0}\left(9^{\circ}\right)$ & $1.769,01$ & 1,71 & $4^{\circ}\left(9^{\circ}\right)$ & $1.800,78$ & 1,73 & $5^{\circ}\left(10^{\circ}\right)$ \\
\hline Pelotas & $1.656,76$ & 1,82 & $4^{\circ}\left(9^{\circ}\right)$ & $1.697,81$ & 1,82 & $3^{\circ}\left(8^{\circ}\right)$ & $1.777,25$ & 1,79 & $3^{\circ}\left(8^{\circ}\right)$ & $1.811,68$ & 1,75 & $3^{\circ}\left(8^{\circ}\right)$ & $1.858,22$ & 1,78 & $4^{\circ}\left(9^{\circ}\right)$ \\
\hline Rio Grande & $1.900,12$ & 2,09 & $2^{\circ}\left(7^{\circ}\right)$ & $2.064,68$ & 2,22 & $2^{\circ}\left(7^{\circ}\right)$ & $2.490,94$ & 2,52 & $2^{\circ}\left(6^{\circ}\right)$ & $3.262,34$ & 3,16 & $2^{\circ}\left(4^{\circ}\right)$ & $3.033,12$ & 2,91 & $2^{\circ}\left(4^{\circ}\right)$ \\
\hline Santa Cruz do Sul & $1.795,78$ & 1,98 & $3^{\circ}\left(8^{\circ}\right)$ & $1.664,18$ & 1,79 & $4^{\circ}\left(9^{\circ}\right)$ & $1.660,10$ & 1,68 & $5^{\circ}\left(10^{\circ}\right)$ & $1.740,77$ & 1,69 & $5^{\circ}\left(10^{\circ}\right)$ & $2.114,66$ & 2,03 & $3^{\circ}\left(8^{\circ}\right)$ \\
\hline Santa Maria & $1.479,45$ & 1,63 & $6^{\circ}\left(11^{\circ}\right)$ & $1.573,20$ & 1,69 & $5^{\circ}\left(10^{\circ}\right)$ & $1.639,07$ & 1,66 & $6^{\circ}\left(11^{\circ}\right)$ & $1.654,42$ & 1,60 & $6^{\circ}\left(11^{\circ}\right)$ & $1.669,72$ & 1,60 & $6^{\circ}\left(11^{\circ}\right)$ \\
\hline Uruguaiana & $1.040,15$ & 1,14 & $8^{\circ}\left(15^{\circ}\right)$ & $1.081,85$ & 1,16 & $8^{\circ}\left(15^{\circ}\right)$ & $1.180,64$ & 1,19 & $8^{\circ}\left(15^{\circ}\right)$ & $1.242,88$ & 1,20 & $7^{\circ}\left(14^{\circ}\right)$ & $1.105,35$ & 1,06 & $8^{\circ}\left(15^{\circ}\right)$ \\
\hline Porto Alegre & $17.728,50$ & 19,51 & - & $17.887,42$ & 19,21 & - & $18.835,64$ & 19,02 & - & $18.553,87$ & 17,97 & - & $18.248,33$ & 17,51 & - \\
\hline $\begin{array}{l}\text { Rio Grande } \\
\text { do Sul }\end{array}$ & $90.881,75$ & 100 & - & $93.101,74$ & 100 & - & $99.037,09$ & 100 & - & $103.262,28$ & 100 & - & $104.243,77$ & 100 & - \\
\hline $\begin{array}{l}\text { PIB Corede Sul e } \\
\% \text { de Pelotas }\end{array}$ & $5.074,61$ & 32,65 & - & $5.319,98$ & 31,91 & - & $5.941,26$ & 29,91 & - & $6.858,04$ & 26,42 & - & $6.731,44$ & 27,61 & - \\
\hline
\end{tabular}

Fonte: elaborada com base nos dados do IPEADATA.

Teoria e Evidência Econômica - Ano 19, n. 41, p. 118-149, jul./dez. 2013 
Tabela A4. PIB real per capita em R \$ de 2000 e ranking - 1999-2009

\begin{tabular}{|c|c|c|c|c|c|c|c|c|c|c|c|c|}
\hline \multirow{2}{*}{ Discriminação } & \multicolumn{2}{|l|}{1999} & \multicolumn{2}{|c|}{2000} & \multicolumn{2}{|l|}{2001} & \multicolumn{2}{|l|}{2002} & \multicolumn{2}{|c|}{2003} & \multicolumn{2}{|l|}{2004} \\
\hline & R\$ & Rank. & R\$ & Rank. & R\$ & Rank. & R\$ & Rank. & $\mathbf{R} \$$ & Rank. & $\mathrm{R} \$$ & Rank. \\
\hline Bento Gonçalves & $11.971,97$ & $2^{\circ}$ & $12.345,50$ & $2^{\circ}$ & $11.736,02$ & $3^{\circ}$ & $11.880,64$ & $3^{\circ}$ & $11.005,63$ & $4^{\circ}$ & $11.695,74$ & $3^{\circ}$ \\
\hline Caxias do Sul & $11.179,42$ & $3^{\circ}$ & $12.048,48$ & $3^{\circ}$ & $11.959,01$ & $2^{\circ}$ & $12.072,01$ & $2^{\circ}$ & $12.052,03$ & $2^{\circ}$ & $12.931,39$ & $2^{\circ}$ \\
\hline Erechim & $8.403,70$ & $6^{\circ}$ & $8.600,70$ & $6^{\circ}$ & $9.191,83$ & $6^{\circ}$ & $8.416,73$ & $7^{\circ}$ & $9.526,00$ & $6^{\circ}$ & $9.106,20$ & $7^{\circ}$ \\
\hline Lajeado & $9.562,65$ & $4^{\circ}$ & $9.722,73$ & $5^{\circ}$ & $9.790,36$ & $5^{\circ}$ & $10.337,77$ & $5^{\circ}$ & $10.775,03$ & $5^{\circ}$ & $11.628,03$ & $4^{\circ}$ \\
\hline Passo Fundo & $8.025,76$ & $7^{\circ}$ & $8.526,85$ & $7^{\circ}$ & $8.061,02$ & $7^{\circ}$ & $8.885,20$ & $6^{\circ}$ & $9.352,51$ & $7^{\circ}$ & $9.116,32$ & $6^{\circ}$ \\
\hline Pelotas & $5.610,27$ & $9^{\circ}$ & $5.207,34$ & $10^{\circ}$ & $5.207,56$ & $10^{\circ}$ & $5.267,62$ & $10^{\circ}$ & $5.044,02$ & $10^{\circ}$ & $5.219,53$ & $10^{\circ}$ \\
\hline Rio Grande & $9.132,35$ & $5^{\circ}$ & $9.918,18$ & $4^{\circ}$ & $10.661,84$ & $4^{\circ}$ & $11.205,43$ & $4^{\circ}$ & $11.400,50$ & $3^{\circ}$ & $11.606,42$ & $5^{\circ}$ \\
\hline Santa Cruz do Sul & $14.393,63$ & $1^{\circ}$ & $13.090,43$ & $1^{\circ}$ & $13.990,17$ & $1^{\circ}$ & $14.904,36$ & $1^{\circ}$ & $15.130,29$ & $1^{0}$ & $16.878,12$ & $1^{\circ}$ \\
\hline Santa Maria & $5.459,55$ & $10^{\circ}$ & $5.416,12$ & $9^{\circ}$ & $5.241,75$ & $9^{\circ}$ & $5.636,11$ & $9^{\circ}$ & $5.634,88$ & $9^{\circ}$ & $5.791,36$ & $9^{\circ}$ \\
\hline Uruguaiana & $5.898,19$ & $8^{\circ}$ & $5.566,40$ & $8^{\circ}$ & $6.189,18$ & $8^{\circ}$ & $6.662,42$ & $8^{\circ}$ & $6.001,33$ & $8^{\circ}$ & $6.464,78$ & $8^{\circ}$ \\
\hline Porto Alegre & $12.279,69$ & $\cdot$ & $12.134,91$ & - & $11.907,26$ & - & $12.326,53$ & $\cdot$ & $11.583,78$ & $\cdot$ & $11.616,66$ & - \\
\hline Corede Sul & $5.857,95$ & $\cdot$ & $5.845,01$ & - & $6.168,55$ & - & $6.283,55$ & $\cdot$ & $6.354,47$ & $\cdot$ & $6.614,45$ & - \\
\hline Rio Grande do Sul & $7.788,78$ & $\cdot$ & $8.030,66$ & $\cdot$ & $8.256,36$ & - & $8.487,57$ & $\cdot$ & $8.765,57$ & $\cdot$ & $8.931,60$ & - \\
\hline \multirow{2}{*}{ Discriminação } & \multicolumn{2}{|l|}{2005} & \multicolumn{2}{|c|}{2006} & \multicolumn{2}{|l|}{2007} & \multicolumn{2}{|l|}{2008} & \multicolumn{2}{|c|}{2009} & \multicolumn{2}{|l|}{ Média } \\
\hline & $\mathrm{R} \$$ & Rank. & R\$ & Rank. & $\mathbf{R} \$$ & Rank. & R\$ & Rank. & R\$ & Rank. & R\$ & Rank. \\
\hline Bento Gonçalves & $12.115,85$ & $3^{\circ}$ & $11.669,35$ & $3^{\circ}$ & $12.033,27$ & $4^{\circ}$ & $11.025,27$ & $5^{\circ}$ & $11.832,23$ & $5^{\circ}$ & $11.755,59$ & $4^{\circ}$ \\
\hline Caxias do Sul & $13.121,20$ & $2^{\circ}$ & $12.584,41$ & $2^{\circ}$ & $13.275,05$ & $2^{\circ}$ & $14.520,57$ & $3^{\circ}$ & $14.110,96$ & $3^{\circ}$ & $12.714,05$ & $2^{\circ}$ \\
\hline Erechim & $8.939,44$ & $6^{\circ}$ & $9.007,11$ & $6^{\circ}$ & $10.140,40$ & $6^{\circ}$ & $10.364,92$ & $6^{\circ}$ & $10.653,87$ & $6^{\circ}$ & $9.304,63$ & $6^{\circ}$ \\
\hline Lajeado & $11.363,48$ & $4^{\circ}$ & $11.543,38$ & $4^{\circ}$ & $11.715,07$ & $5^{\circ}$ & $11.912,95$ & $4^{\circ}$ & $12.433,24$ & $4^{\circ}$ & $10.980,42$ & $5^{\circ}$ \\
\hline Passo Fundo & $8.549,14$ & $7^{\circ}$ & $8.687,19$ & $7^{\circ}$ & $9.539,04$ & $7^{\circ}$ & $9.742,50$ & $8^{\circ}$ & $9.829,19$ & $7^{\circ}$ & $8.937,70$ & $7^{\circ}$ \\
\hline Pelotas & $5.091,20$ & $10^{\circ}$ & $5.204,94$ & $10^{\circ}$ & $5.437,56$ & $10^{\circ}$ & $5.536,57$ & $10^{\circ}$ & $5.669,18$ & $10^{\circ}$ & $5.317,80$ & $10^{\circ}$ \\
\hline Rio Grande & $9.870,47$ & $5^{\circ}$ & $10.663,35$ & $5^{\circ}$ & $12.800,11$ & $3^{\circ}$ & $16.687,78$ & $1^{\circ}$ & $15.449,07$ & $2^{\circ}$ & $11.763,23$ & $3^{\circ}$ \\
\hline Santa Cruz do Sul & $15.847,01$ & $1^{\circ}$ & $14.548,18$ & $1^{\circ}$ & $14.384,52$ & $1^{\circ}$ & $14.956,32$ & $2^{\circ}$ & $18.020,28$ & $1^{\circ}$ & $15.103,94$ & $1^{\circ}$ \\
\hline Santa Maria & $5.852,18$ & $9^{\circ}$ & $6.177,71$ & $9^{\circ}$ & $6.397,26$ & $9^{\circ}$ & $6.419,40$ & $9^{\circ}$ & $6.437,59$ & $9^{\circ}$ & $5.860,36$ & $9^{\circ}$ \\
\hline Uruguaiana & $8.199,84$ & $8^{\circ}$ & $8.538,28$ & $8^{\circ}$ & $9.341,67$ & $8^{\circ}$ & $9.859,65$ & $7^{\circ}$ & $8.788,59$ & $8^{\circ}$ & $7.410,03$ & $8^{\circ}$ \\
\hline Porto Alegre & $12.775,25$ & - & $12.847,34$ & - & $13.488,42$ & - & $13.251,22$ & $\cdot$ & $12.992,37$ & $\cdot$ & $12.473,04$ & - \\
\hline COREDE Sul & $6.052,93$ & $\cdot$ & $6.332,08$ & - & $7.060,57$ & - & $8.145,36$ & - & $7.989,08$ & $\cdot$ & $6.609,46$ & ${ }^{\circ}$ \\
\hline Rio Grande do Sul & $8.672,16$ & - & $8.840,89$ & & $9.364,98$ & - & $9.729,27$ & - & $9.786,01$ & - & $8.786,71$ & - \\
\hline
\end{tabular}

Fonte: elaborada com base nos dados do IPEADATA. 
Tabela A5. Evolução da participação relativa do PIB real setorial no PIB real total - 1999-2009

\begin{tabular}{|c|c|c|c|c|c|c|c|c|c|c|c|c|c|c|c|c|c|c|c|c|c|c|c|c|}
\hline \multirow{2}{*}{ Discriminação } & \multicolumn{4}{|c|}{1999} & \multicolumn{4}{|c|}{2000} & \multicolumn{4}{|c|}{2001} & \multicolumn{4}{|c|}{2002} & \multicolumn{4}{|c|}{2003} & \multicolumn{4}{|c|}{2004} \\
\hline & AGR & IND & SER & IMP & AGR & IND & SER & IMP & AGR & IND & SER & IMP & AGR & IND & SER & IMP & AGR & IND & SER & IMP & AGR & IND & SER & IMP \\
\hline Bento Gonçalves & 2,19 & 35,85 & 48,04 & 13,93 & 2,28 & 38,13 & 45,51 & 14,08 & 2,96 & 35,93 & 46,71 & 14,39 & 3,66 & 35,56 & 47,27 & 13,51 & 3,53 & 36,29 & 44,33 & 15,85 & 3,51 & 36,93 & 43,65 & 15,92 \\
\hline Caxias do Sul & 1,93 & 32,34 & 53,15 & 12,59 & $\mid 1,78$ & 34,08 & 50,01 & 14,14 & 2,17 & 32,65 & 49,85 & 15,34 & 2,15 & 32,83 & 50,49 & 14,52 & 2,19 & 34,43 & 48,03 & 15,34 & 1,87 & 39,19 & 44,28 & 14,66 \\
\hline Erechim & 3,51 & 23,94 & 61,36 & 11,18 & 3,66 & 27,28 & 57,45 & 11,61 & 2,10 & 24,01 & 60,33 & 13,56 & 2,18 & 27,37 & 57,34 & 13,11 & 2,62 & 26,57 & 56,90 & 13,91 & 2,36 & 33,32 & 52,38 & 11,94 \\
\hline Lajeado & 1,94 & 32,97 & 52,28 & 12,81 & 1,99 & 34,19 & 50,70 & 13,12 & 1,20 & 31,17 & 52,59 & 15,04 & 1,11 & 28,80 & 55,53 & 14,57 & 1,18 & 30,86 & 53,49 & 14,46 & 0,95 & 35,16 & 50,36 & 13,53 \\
\hline Passo Fundo & 2,38 & 16,17 & 71,34 & 10,12 & 2,19 & 16,64 & 69,73 & 11,44 & 3,14 & 16,77 & 67,97 & 12,12 & 2,58 & 16,73 & 69,29 & 11,41 & 3,40 & 18,51 & 65,86 & 12,23 & 2,15 & 21,33 & 64,68 & 11,84 \\
\hline Pelotas & 2,52 & 19,91 & 67,83 & 9,73 & 2,63 & 19,17 & 68,46 & 9,74 & 3,38 & 18,68 & 67,75 & 10,19 & 3,18 & 18,14 & 69,10 & 9,57 & 3,65 & 18,28 & 66,73 & 11,33 & 4,12 & 20,21 & 65,62 & 10,06 \\
\hline Rio Grande & 2,33 & 26,95 & 53,82 & 16,89 & 2,01 & 30,91 & 51,35 & 15,73 & 2,56 & 32,02 & 47,50 & 17,92 & 2,04 & 31,95 & 44,55 & 21,45 & 2,31 & 40,63 & 44,90 & 12,17 & 2,69 & 40,24 & 43,01 & 14,06 \\
\hline Santa Cruz do Sul & 3,31 & 39,24 & 38,49 & 18,96 & 3,34 & 38,64 & 39,41 & 18,61 & 3,94 & 39,37 & 38,42 & 18,28 & 3,37 & 39,91 & 39,36 & 17,35 & 4,05 & 40,35 & 37,51 & 18,09 & 3,67 & 41,36 & 35,51 & 19,47 \\
\hline Santa Maria & 2,82 & 11,57 & 76,17 & 9,43 & 2,45 & 12,96 & 74,27 & 10,32 & 3,06 & 12,36 & 73,65 & $\mid 10,94$ & 3,05 & 12,01 & 74,60 & 10,34 & 3,61 & 12,26 & 73,10 & 11,03 & 3,36 & 13,73 & 72,24 & 10,67 \\
\hline Uruguaiana & 14,38 & 18,29 & 58,83 & 8,49 & 9,78 & 19,55 & 61,54 & 9,13 & 12,96 & 18,44 & 58,67 & 9,94 & 14,54 & 17,00 & 49,60 & 18,85 & 16,97 & 19,45 & 53,89 & 9,70 & 19,08 & 19,45 & 50,66 & 10,80 \\
\hline Porto Alegre & 0,05 & 11,95 & 73,89 & 14,11 & 0,05 & 12,75 & 71,78 & 15,43 & 0,06 & 12,16 & 71,66 & 16,12 & 0,08 & 11,53 & 72,60 & 15,80 & 0,07 & 11,90 & 71,44 & 16,59 & 0,06 & 13,16 & 70,83 & 15,96 \\
\hline Corede Sul & 9,93 & 20,37 & 58,85 & 10,81 & $\mid 8,87$ & 22,52 & 57,90 & 10,66 & 11,03 & 22,21 & 55,01 & 11,70 & 10,16 & 22,24 & 54,25 & 13,31 & 11,94 & 25,47 & 52,68 & 9,86 & $\mid 12,92$ & 25,85 & 50,98 & 10,20 \\
\hline Rio Grande do Sul & 7,82 & 23,87 & 56,67 & $\mid 11,64$ & 7,31 & 26,20 & 54,34 & 12,15 & 9,01 & 24,54 & 53,23 & 13,23 & 8,76 & 24,41 & 54,06 & 12,78 & 11,19 & 24,57 & 51,55 & 12,70 & 9,20 & 27,33 & 50,32 & 13,15 \\
\hline
\end{tabular}

\begin{tabular}{|c|c|c|c|c|c|c|c|c|c|c|c|c|c|c|c|c|c|c|c|c|}
\hline \multirow{2}{*}{ Discriminação } & \multicolumn{4}{|c|}{2005} & \multicolumn{4}{|c|}{2006} & \multicolumn{4}{|c|}{2007} & \multicolumn{4}{|c|}{2008} & \multicolumn{4}{|c|}{2009} \\
\hline & AGR & IND & SER & IMP & AGR & IND & SER & IMP & AGR & IND & SER & IMP & AGR & IND & SER & IMP & AGR & IND & SER & IMP \\
\hline Bento Gonçalves & 2,87 & 34,28 & 48,27 & 14,58 & 2,61 & 33,32 & 49,65 & 14,42 & 2,28 & 32,61 & 50,90 & 14,20 & 2,22 & 29,72 & 52,39 & 15,67 & 2,37 & 33,04 & 49,73 & 14,86 \\
\hline Caxias do Sul & 1,43 & 36,66 & 46,82 & 15,10 & 1,75 & 36,02 & 47,73 & 14,50 & 1,46 & 35,02 & 49,17 & 14,35 & 1,13 & 33,80 & 48,82 & 16,25 & 1,39 & 36,32 & 47,64 & 14,65 \\
\hline Erechim & 1,52 & 32,47 & 53,89 & 12,11 & 2,04 & 28,68 & 57,36 & 11,92 & 2,14 & 30,78 & 55,95 & 11,13 & 2,21 & 31,84 & 54,21 & 11,74 & 1,76 & 35,39 & 52,21 & 10,65 \\
\hline Lajeado & 0,74 & 31,65 & 53,56 & 14,05 & 0,89 & 30,16 & 55,37 & 13,58 & 1,00 & 28,79 & 57,57 & 12,64 & 0,81 & 29,13 & 56,78 & 13,28 & 0,77 & 31,50 & 54,95 & 12,78 \\
\hline Passo Fundo & 1,02 & 17,14 & 69,61 & 12,23 & 2,11 & 14,69 & 71,97 & 11,23 & 2,16 & 15,05 & 72,28 & 10,51 & 2,40 & 15,92 & 70,58 & 11,09 & 2,03 & 19,49 & 68,24 & 10,24 \\
\hline Pelotas & 2,76 & 18,01 & 69,42 & 9,81 & 3,20 & 17,11 & 70,53 & 9,16 & 2,97 & 16,00 & 72,68 & 8,35 & 3,25 & 16,69 & 71,06 & 9,00 & 3,62 & 18,00 & 69,97 & 8,42 \\
\hline Rio Grande & 2,69 & 26,60 & 44,96 & 25,75 & 2,57 & 29,41 & 44,54 & 23,48 & 2,22 & 30,38 & 41,06 & 26,34 & 1,94 & 27,55 & 43,12 & 27,38 & 2,15 & 29,15 & 44,30 & 24,40 \\
\hline Santa Cruz do Sul & 2,83 & 39,42 & 39,44 & 18,32 & 3,68 & 35,59 & 42,04 & 18,69 & 3,02 & 33,69 & 44,93 & 18,36 & 3,00 & 36,01 & 42,84 & 18,14 & 2,65 & 41,90 & 37,72 & 17,73 \\
\hline Santa Maria & 1,89 & 13,20 & 74,20 & 10,72 & 2,76 & 13,52 & 73,83 & 9,89 & 2,85 & 12,86 & 75,23 & 9,07 & 3,16 & 12,85 & 74,50 & 9,49 & 3,01 & 14,32 & 73,79 & 8,89 \\
\hline Uruguaiana & 7,48 & 15,10 & 41,33 & 36,09 & 9,45 & 15,71 & 39,38 & 35,46 & 6,63 & 12,92 & 36,92 & 43,53 & 10,97 & 10,53 & 34,76 & 43,74 & 13,49 & 9,80 & 38,38 & 38,33 \\
\hline Porto Alegre & 0,05 & 11,65 & 69,55 & 18,74 & 0,06 & 11,22 & 69,56 & 19,17 & 0,05 & 10,73 & 71,75 & 17,48 & 0,05 & 11,28 & 70,42 & 18,25 & 0,06 & 12,31 & 71,18 & 16,45 \\
\hline Corede Sul & 9,75 & 19,75 & 55,02 & 15,40 & 9,97 & 20,41 & 54,98 & 14,57 & 9,77 & 20,64 & 53,48 & 16,05 & 9,98 & 20,40 & 52,00 & 17,57 & 11,00 & 21,21 & 52,26 & 15,46 \\
\hline Rio Grande do Sul & 6,08 & 25,98 & 53,74 & 14,20 & 8,02 & 24,33 & 54,13 & 13,53 & 8,56 & 23,17 & 55,31 & 12,96 & 9,08 & 22,91 & 54,35 & 13,66 & 8,63 & 25,56 & 53,32 & 12,49 \\
\hline
\end{tabular}

Fonte: elaborada com base nos dados do IPEADATA. 